\title{
Communal Land and Agricultural Productivity is
}

\author{
Charles Gottlieb ${ }^{2,3,4}$, Jan Grobovšek ${ }^{1}$
}

September 26, 2016

\begin{abstract}
Communal land tenure is a typical feature of many developing countries. Such tenure regimes implement a "use it or lose it" principle by imposing restrictions to land transferability that are enforced via the threat of expropriation. This paper measures the distortionary impact of communal land in a dynamic general equilibrium model of occupational selection, calibrated to Ethiopia. We find that lifting restrictions on land transferability lowers agricultural employment by $19 \%$ and increases GDP by $7 \%$. It also results in a large reduction in the ratio between non-agricultural and agricultural productivity, by $40 \%$ in real and $44 \%$ in nominal terms. Limited land transferability rationalizes a substantial fraction of the large agricultural productivity gap in poor economies. The associated loss in aggregate productivity, though, is comparatively minor.

Keywords: Agricultural productivity, Growth and development, Misallocation, Land, Africa, Ethiopia.

JEL: O10, O13, O40, O55, Q15.

\footnotetext{
${ }^{\text {th }}$ First version: September 2014. This paper has benefited from helpful suggestions by Tasso Adamopoulos, Tekie Alemu, Douglas Gollin, Madina Guloba, Roland Hodler, Philipp Kircher, Winfried Koeniger, Francis Mwesigye and Alemayehu Taffesse, as well as seminar participants at the Atlanta Fed, Cambridge, Western Ontario, York, McMaster, McGill, the North American Econometric Society Meeting (Minneapolis), CEPR Macroeconomic and Growth Meeting, EDRI (Addis Ababa), EPRC (Kampala), DEGIT XXI Conference, and World Bank Land and Poverty Conference 2015. The financial support from DFID/ESRC (ES/L012499/1) is gratefully acknowledged.

Email addresses: charles.gottlieb@unisg.ch (Charles Gottlieb), jan.grobovsek@ed.ac.uk (Jan Grobovšek)

${ }^{1}$ University of Edinburgh, School of Economics

${ }^{2}$ University of St. Gallen, School of Economics and Political Science

${ }^{3}$ Centre for Macroeconomics (CFM), University of Cambridge

${ }^{4}$ Nuffield College
} 


\section{Introduction}

The labor productivity gap between rich and poor countries is larger in the agricultural sector than in the rest of the economy. This is consistent with three non-exclusive interpretations. First, poor economies manifest especially pronounced inefficiencies in the agricultural sector. Second, poor economies devote excessive amounts of labor to agriculture. Third, in poor economies - even more than in rich ones - the farming sector is populated by relatively unskilled workers. Are there any particular policies that generate these outcomes and hence depress relative agricultural productivity? And, if yes, do these policies also entail large losses in aggregate productivity?

The aim of this paper is to evaluate one such policy institution, communal agricultural land tenure. It is prevalent across the developing world and most notably in Sub-Saharan Africa, the focus of our analysis. The term "communal" is a catch-all for many characteristics. A defining one is that individual land property rights are not complete because the ultimate allocative control is vested in either the community or the state. More precisely, we focus on a single specificity, namely limited transferability of land user rights. Individuals are not free to sell and rent out their land. If they do, land can be expropriated and reallocated to other users.

Our first contribution is an equilibrium model that highlights the distortions created by limits to land transferability. The framework consists is an off-the-shelf selection model where agents make an occupational choice between agriculture and nonagriculture. Non-agricultural workers are employees while agricultural workers choose land operations to run individual farms. Communal land is held through individual user rights, which are renewed periodically unless expropriation occurs. The key features of the land regime are as follows. First, communal land sales are prohibited and the risk of expropriation rises in the fraction of the holding that is rented out. Thus, individuals who do not rent out their land face no expropriation threat; individuals who rent out all of their land (non-farmers) face the highest threat. Second, expropriated land is reallocated exclusively to farmers, following a probabilistic rule that favors land-poor individuals. 
Our second contribution is the quantification of the model to measure the impact of communal land tenure on the aggregate economy. The calibration is based on Ethiopia, namely the panel component of the LSMS-ISA rounds, complemented by our own small-scale household survey. Ethiopia is an ideal benchmark economy because typical features of communal land tenure are legally codified. ${ }^{5}$ Our key result is then the comparison of the calibrated economy to a counterfactual one with no communal land. Removing limits to land transferability generates a large increase in two relative labor productivity measures of interest. Real labor productivity in non-agriculture relative to agriculture drops by $40 \%$, while its nominal counterpart (relative value-added per worker in local prices) declines by even more, 44\%. Moreover, agricultural employment decreases by a considerable 19 percent. As for GDP, it experiences a non-negligible but ultimately quite modest rise of $7 \%$.

This paper connects with several strands of the literature. First, we address the fact that poor countries have puzzlingly low real labor productivity in agriculture (Restuccia et al., 2008). According to our own estimates, real productivity in nonagriculture relative to agriculture - commonly referred to as the real agricultural productivity gap (APG) - is roughly 7.9 times higher in the poorest compared to the richest decile of countries. ${ }^{6}$ Communal land tenure helps explain this enormous factor difference. Thinking of Ethiopia as a representative economy of the poorest decile of countries, the elimination of land transfer restrictions reduces the real APG vis-à-vis the richest countries to $7.9 \times(1-0.4)=4.7$. One of the reasons why communal land depresses real agricultural productivity is because land operations are misallocated. Following our model, $73 \%$ of farmers choose excessive land operations. They do so to lower the risk of future expropriation by limiting the amount of land that they rent

\footnotetext{
${ }^{5}$ This formalization allows for a clean mapping from the data to the model. In particular, we exploit the fact that all land in Ethiopia has limits on transferability, that any land sales are prohibited, and that land ownership is tied to continuous nearby residence.

${ }^{6}$ Restuccia et al. (2008) and Caselli (2005) estimate it to be roughly a factor of 10 around the year 1985. Our update of these measures based on 2005 data and on an alternative price deflator, confirms that the factor difference is huge. Please see Appendix 9.1.1 for details. Also, Gollin et al. (2014a) confirm that such a large factor is consistent with readily available real productivity measures in the most important staple crops.
} 
out.

Second, this paper addresses nominal productivity in non-agriculture relative to agriculture. It is roughly 3.5 times higher in the poorest compared to the richest decile of countries. Lifting land transfer restrictions in our representative poor economy reduces the factor difference in the nominal APG relative to rich countries to $3.5 \times(1-0.44)=2$. The relatively low agricultural value-added per worker in poor countries is often interpreted as a reflection of barriers to inter-sectoral labor mobility that prevent the equalization of marginal products across sectors. ${ }^{7}$ Communal land tenure is exemplary of such distortions. Holding everything else constant, individuals prefer to be active in agriculture. Not only does selecting into agriculture dampen the risk of future expropriation, it also promises the benefit of future transfers of communal land.

Third, both the real and nominal APG in poor countries may be due to relatively low intensity and efficiency units of labor in agriculture. Gollin et al. (2014b) find that adjustments to hours worked and human capital reduce the cross-country APG factor difference by up to a half. It appears that in poorer economies the agricultural sector employs particularly many unskilled workers. The selection model of Lagakos and Waugh (2013) rationalizes such a pattern as an efficient outcome. Low TFP, in conjunction with food subsistence requirements, implies a large agricultural sector that disproportionately attracts unskilled workers. ${ }^{8}$ This mechanism is also present in our framework, though part of the selection is inefficient. Communal land tenure has a marked effect on individuals with low skills in both agricultural and nonagricultural activities. In absence of communal land, these marginal individuals weakly

\footnotetext{
${ }^{7}$ This follows from the assumption that marginal and average products are proportional. The nominal APG is then closely related to the sectoral wage gap and hence the classical "dual-economy" conundrum studied in Lewis (1954) and Harris and Todaro (1970). See also Vollrath (2009) and McMillan and Rodrik (2011).

${ }^{8}$ Young (2013) also finds that much of the urban-rural gap in real consumption across countries can be explained by differences in unobserved sector-specific skills. According to Herrendorf and Schoellman (2015) the wage gap in agriculture relative to non-agriculture in several large countries (excluding Sub-Saharan Africa) is in fact explained away by observable years of education once cross-sectoral differences in returns to human capital are taken into account.
} 
prefer the non-agricultural sector. When land is communal, in contrast, they are occupationally constrained to farming. Being sizable, this group has a significant impact on relative sectoral productivity measures, dragging down the productivity of whichever sector they are present in.

This paper follows in the footsteps of a growing macro development literature that explains the APG in developing countries as resulting from distortions to land allocation. ${ }^{9}$ Adamopoulos and Restuccia (2014b) are among the first to study misallocation in agriculture through the lens of a model where farmer-operators are heterogeneous in skills. They find that matching typical features of the farm size distribution in developing countries - a low mean and low dispersion in farm size - via generic wedges could rationalize an important fraction of the real APG. Restuccia and Santaeulàlia-Llopis (2015) and Adamopoulos et al. (2016) go a step further by using micro data to back out farm-specific TFP as well as wedges in Malawi and China, respectively. In both cases the authors compute huge gains in aggregate agricultural productivity from removing wedges that shift resources from skilled to unskilled farmers. Also, both in Malawi and China the underlying distortions appear to be associated with difficulties in transferring land user rights across operators. Chen (2016) investigates how exogenous non-transferable land endowments affect agricultural productivity in an environment of sectoral selection. In contrast to his quantification on Malawian data, we find that the friction causes a similar quantitative effect on the real APG, but a considerably weaker impact on agricultural employment and especially GDP. ${ }^{10}$

Relative to the above contributions our paper provides a micro foundation for distortions based on an explicit policy. By having agents take forward-looking choices, distortionary policies are circumvented more easily. The degree of misallocation depends

\footnotetext{
${ }^{9}$ The APG has also been addressed by distortions encouraging home work in the rural sector (Gollin et al., 2004), distortions to intermediate input use in agriculture (Restuccia et al., 2008), transportation costs (Gollin and Rogerson, 2014), and incomplete financial markets (Donovan, 2016).

${ }^{10}$ Our modeling choice differs because we allow for a high degree of land rental market activity, in accordance with most evidence from Sub-Saharan Africa. Farmers can rent out a limited fraction of their land without facing substantial expropriation risk, which undoes much of the operational misallocation.
} 
ultimately on the correlation between communal land ownership and agricultural (as well as non-agricultural) skills. This correlation arises as an endogenous object from the stationary distribution. The fact that the model is dynamic, therefore, is key. The focus on a specific policy institution is closest in spirit to Adamopoulos and Restuccia (2014a). They provide a detailed case study of misallocation due to a sudden land reform and farm size caps in the Philippines. They precisely quantify a one-off event, but their underlying institutional arrangement is very distinct. We study a process of slow but continuous land reallocation where agents take actions to fend off the threat of expropriation, and where the ultimate distribution of communal land ownership evolves endogenously.

We also touch base with a sizable microeconomic literature on tenure insecurity and agricultural productivity. A limited number of these papers focus on misallocation across users. The contributions in Holden et al. (2009), for example, provide evidence that land security boosts allocative gains in several Sub-Saharan African countries. In the Ethiopian context de Brauw and Mueller (2012) find that perceptions of land tenure security foster increased rural-urban migration. A study on the Dominican Republic by Macours et al. (2010) finds that insecure land rights prompt owners to limit land rentals to close kin only, thus preventing allocation to more efficient users. In the case of Mexico, de Janvry et al. (2015) document that formal land titling enabled a marketbased reallocation (through sales and rentals) to more productive land-poor from less productive land-rich farmers, and a stronger outmigration of the latter. These papers measure misallocation in a partial equilibrium setting while our paper stresses equilibrium adjustments, which turn out to be crucial. Specifically, we find that communal land tenure substantially increases the rental rate of land. This is because it induces a larger number of farmers and because these farmer run excessive land operations, thus stifling the rental market.

One aspect that we abstract from are productive investment incentives in the face of tenure insecurity. This is beyond the scope of the present paper, but we do note that our framework is well-suited for such an extension. Suffice it to say that the 
empirical literature on the effect of increasing tenure security on investment in SubSaharan Africa has been very active, identifying several pathways. First, investment can increase as the likelihood of recouping its returns is higher, as shown by Besley (1995) and Goldstein and Udry (2008) in studies on Ghana, by Ali et al. (2011) in Ethiopia, and by Fenske (2011) in several countries in West Africa. Second, land investment may also decrease as individuals with weak titles feel more compelled to secure their user rights via intensive outlays - see for instance Place and Otsuka (2002) and Deininger and Jin (2006). Third, securing land rights may raise collateral to be used for credit and investment (Feder, 1985), though there is little evidence of such a channel in Africa (Brasselle et al., 2002).

The next Section described the institutional characteristics of communal land. Section 3 lays out the model, followed by its equilibrium characterization in Section 4. In Section 5 we discuss the calibration of the model. Section 6 presents the main findings. Section 7 investigates a number of quantitative experiments. Section 8 concludes.

\section{Institutional Environment}

\subsection{Communal Land across Countries}

Communal land tenure regimes are present in many developing countries, in particular in Sub-Saharan Africa. There, land tenure is often prescribed by customary law that varies across as well as within countries (Pande and Udry, 2005). Its features, however, can be summed up by the principle of "use it or lose it" whereby rights to land can be claimed only through the use of land, and only for the duration of that use (Sjaastad and Bromley, 1997). ${ }^{11}$ This principle restricts the commercialisation of land, whether that be through sales or rentals. Land sales require the consent of extended family members, clan leaders, or chiefs; they may block them on the notion that one cannot sell something that one had been granted by the community (Atwood, 1990;

\footnotetext{
${ }^{11}$ Some communal regimes also feature collective ownership, for example with regards to pastures. The resulting classical incentive problems are not addressed here as our framework focuses on exclusive user rights.
} 
Bruce and Migot-Adholla, 1994). Also, farmers are reluctant to rent out their land to tenants who, by virtue of working it, can stake a claim to ownership. ${ }^{12}$ Such a threat is particularly likely for landlords who migrate; owners in effect invest "guard labor" to prevent expropriation (Field, 2007). If expropriated, the user rights to the land are tacitly or explicitly reallocated by local authorities. One particular concern in the reallocation process is to prevent the emergence of a large landless class of farmers. This is reflected in the comparatively low inequality in land ownership in most Sub-Saharan African countries (Place, 2009). In some countries, all land belongs to the state and the principles of customary land tenure apply formally (e.g. in Ethiopia and Tanzania). Beyond Sub-Saharan Africa, formal or informal rules can be found across other parts of the world, prominent examples being the ejidos in Mexico (de Janvry et al., 2015) or public land in China (Jacoby et al., 2002; Deininger and Jin, 2009) and Vietnam (Do and Iyer, 2008).

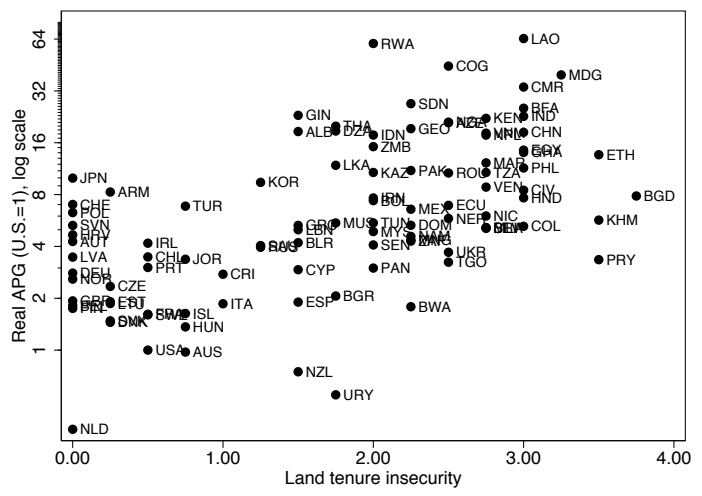

(a) Real

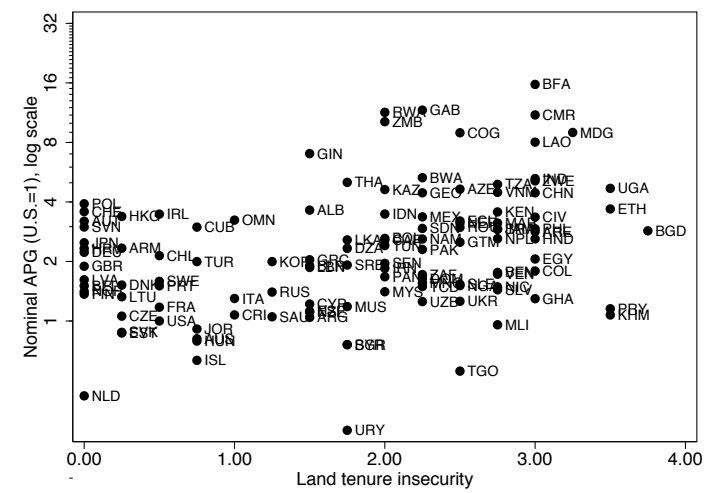

(b) Nominal

Figure 1: Relative agricultural productivity and land tenure insecurity.

There exists no single cross-country metric for limited land transferability. As it is enforced via expropriation, one proxy is tenure insecurity. Figure 1 shows the cross-country relationship between a tenure insecurity index and productivity in non-

\footnotetext{
${ }^{12}$ Bomuhangi et al. (2011) show that land rentals are especially risky for disadvantaged owners such as women.
} 
agriculture relative to agriculture (both real and nominal). ${ }^{13}$ The statistically significant correlation suggests that countries with higher tenure insecurity feature a larger APG, both in real and nominal terms, which serves as a motivation for our analysis. ${ }^{14}$

\subsection{Land Tenure in Ethiopia}

Our quantification is based on Ethiopia, an ideal benchmark economy for our purposes. It is a large country of just over 100 million inhabitants that is representative of the poorer economies of Sub-Saharan Africa. ${ }^{15}$ With respect to measurement, customary law poses the difficulty of being informal as well as diverse across areas and ethnicities within the same country. Ethiopia's communal land tenure regime, by contrast, is codified in law. While some details of the legal architecture vary across federal regions, its main features are identical. These properties facilitate the mapping from our proposed model to the data.

Up until 1975 Ethiopia's land tenure system had feudal characteristics. The majority of land was granted by the emperor to absentee landlords and worked by tenant sharecroppers (Rahmato, 1984). Following the socialist revolution, farms were nationalized and collectivized. After the departure of the Derg regime in 1991, farms were de-collectivized and households were granted permanent use rights. Renting land and hiring of labor were legalized again, and major land redistributions stopped, except in Amhara where one last large scale land redistribution occurred in 1997 (Benin and Pender, 2009). The fundamental principles governing land tenure have remained intact since 1991, codified in the 1997 Constitution.

\footnotetext{
${ }^{13}$ The land tenure insecurity index is computed by CEPII and is a composite measure of several factors. See Appendix 9.1.2 for details on the index and the regression.

${ }^{14}$ The tenure insecurity index, besides accounting for land expropriation, also accounts for formal land titling. In Sub-Saharan Africa only about 10 percent of agricultural land is registered (Byamugisha, 2013). The absence of official titles, however, does not necessarily imply low transferability, nor does their presence guarantee free transactions. This is well documented for tenure regimes in Côte d'Ivoire and Ghana by Pande and Udry (2005).

${ }^{15}$ According to World Bank data for 2012, Ethiopia's GDP per capita in PPP is 1,256 USD, its agricultural employment share is $73 \%$, and it disposes of 0.16 hectares of arable land per capita. The corresponding figures for the average of Sub-Saharan Africa are 3,241 USD, 57\%, and 0.22 hectares per capita. Also, relative to U.S., Ethiopia's real and nominal APG is 14.3 and 3.7, respectively. The unweighted country average for Sub-Saharan Africa is 8.3 and 2.6, respectively.
} 
The existing legal framework has three de jure prescriptions regarding land transferability that will guide our modeling choice. First, according to the Constitution of Ethiopia "Land is a common property of the Nations, Nationalities and Peoples of Ethiopia and shall not be subject to sale or to other means of exchange." This declares all attempts of land sales and mortgages as illegal, and circumscribes land rental activities. Second, the Regional Land Proclamations (2007) set limits on the duration and amount of land that can be rented out. Under "traditional technology" these vary between three years everywhere except for Amhara where it is twenty-five years, and between $50 \%$ of land holdings in Oromia and Tigray to 100\% in Amhara and in Southern Nations, Nationalities, and Peoples' Region. Third, the Federal Land Proclamation (2005) defines an additional restriction on land transferability: land can be leased, but only without causing displacement, i.e. migration (Deininger et al., 2008).

The legal framework of land expropriation coincides with the de facto perceptions of the law by households. The Ethiopian Rural Household Survey (ERHS), a panel dataset of six rounds collected between 1994 and 2004, contains questions on the perception of different dimensions of land rights. Based on that dataset, Deininger and Jin (2006) and Dercon and Krishnan (2010) show that expropriation threatens those that do not make continuous and productive use of their land. In particular, Dercon and Krishnan (2010) show that the perceived tenure security is weaker on rented as opposed to non-rented plots. This evidence strengthens the argument that communal land expropriation is more likely to occur on land that is operated by someone other than its owner. Moreover, Deininger et al. (2003) estimate that the household's expectation of losing land, controlling for regional variation, increases by 10 percent if the household head has an off-farm employment. This shows that continued enjoyment of land user rights is contingent on physical residence in the village (Rahmato, 2003).

The Ethiopian legal framework further prescribes how land user rights are acquired. The Constitution of Ethiopia states that "Ethiopian peasants have right to obtain land without payment." Also, one of the guiding principles of the Poverty Reduction Strategy Paper issued by the Federal Government is to grant access to land to every individual 
who wants to make a livelihood from farming (Rahmato, 2004). In contrast to this de jure evidence, there is relatively little research on de facto outcomes. Based on the ERHS dataset, Deininger et al. (2003) provide evidence that land reallocations among farmers have been driven mainly by political concerns rather than economic ones. ${ }^{16}$

\section{A Model of Communal Land}

\subsection{Individuals and Stand-In Household}

The economy is populated by a unit measure of infinitely lived individuals. These maximize the expected present discounted value of revenue $b$. Time is discrete and discounted at the factor $\beta \in(0,1)$. An individual's state space $x \equiv\left\{z_{a} \times z_{n} \times l_{c}\right\}$ is defined over the following three dimensions: (i) his productive skill in the agricultural sector, $z_{a}>0$; (ii) his productive skill in the non-agricultural sector, $z_{n}>0$; and (iii) his endowment of communal land, $l_{c} \geq 0$. Individual skills are exogenous and drawn from a joint cumulative distribution, $\left\{z_{a}, z_{n}\right\} \sim \Psi\left(z_{a}, z_{n}\right)$. With probability $\zeta \in[0,1]$ the individual's entire skill set is drawn again in the following period, and otherwise remains unchanged. ${ }^{17}$ Communal land holdings $l_{c}$, on the other hand, evolve endogenously. Let $H(x)$ denote the endogenous cumulative distribution function of individual states.

Consumption decisions occur at the level of the aggregate economy by means of a stand-in household. The household maximizes the standard period utility

$$
U\left(C_{a}, C_{n}\right)=\eta \log \left(C_{a}-\bar{a}\right)+(1-\eta) \log C_{n}
$$

where $C_{a}$ and $C_{n}$ denote consumption of agricultural and non-agricultural goods, respectively. The parameter $\eta>0$ represents the relative preference for agricultural

\footnotetext{
${ }^{16}$ Additional evidence by Ege (1997) further emphasizes the political dimensions associated with land reallocation in Ethiopia.

${ }^{17}$ The variation of skills through time is not an essential feature of the model. We use it for two reasons. First, it adds an additional realistic notion at no cost to tractability. Second, as will become clear further on, it rules out degenerate stationary equilibria with zero expropriation and reallocation.
} 
goods, which are also subject to a subsistence requirement $\bar{a}>0$. The stand-in household's budget is given by

$$
p C_{a}+C_{n}=\int b(x) \mathrm{d} H(x)+r L_{p}
$$

The household collects individual revenues $b$ in addition to receiving income from renting out private land $L_{p}$ at the rate $r$. The price of agricultural goods is $p$ while that of non-agricultural goods is normalized to unity. The resulting optimality condition $\eta /\left(C_{a}-\bar{a}\right)=p(1-\eta) / C_{n}$ is the standard driving force of structural transformation. ${ }^{18}$

\subsection{Occupational Choice and Production}

In each time period an individual of type $x$ disposes of one unit of labor and chooses his current occupation: agriculture $\left(\mathbb{1}_{a}=1\right)$ or non-agriculture $\left(\mathbb{1}_{a}=0\right)$. In nonagriculture, there is a representative firm that produces non-agricultural output $Y_{n}$ according to a linear production technology:

$$
Y_{n}=\int\left[1-\mathbb{1}_{a}(x)\right] z_{n}(x) \mathrm{d} H(x)
$$

The firm's optimality condition under perfect competition implies that labor income equals $w_{n}\left(z_{n}\right)=z_{n}$.

In agriculture, by contrast, each individual runs his own farm. The farm's output $y_{a}$ depends on the individual's agricultural skill $z_{a}$ as well as the choice of land operations $l \geq 0$ according to the following production technology:

$$
y_{a}\left(z_{a}, l\right)=z_{a}^{1-\gamma} l^{\gamma}
$$

The production technology is kept deliberately simple to single out the interplay be-

\footnotetext{
${ }^{18}$ If the utility function applied directly to individuals, its curvature would imply a consumptionsmoothing motive for individuals facing variations in skills. We would like to abstract from such concerns here, which is why individual utility is assumed to be linear. The trade-off between agricultural and non-agricultural goods, on the other hand, is preserved by the use of the stand-in household. Our framework, however, is not suited to analyze individual welfare.
} 
tween fixed farmer skills and land operations. ${ }^{19}$ Land is remunerated at the rate $r$ and agricultural output is valued at $p$. The farmer's implied labor income (or equivalently profits) amounts to the difference between sales and land rental payments, $w_{a}\left(z_{a}, l\right)=p y_{a}\left(z_{a}, l\right)-r l$.

The individual's budget constraint reads as follows:

$$
b= \begin{cases}w_{n}\left(z_{n}\right)+r l_{c}=z_{n}+r l_{c} & \text { if } \mathbb{1}_{a}=0 \\ w_{a}\left(z_{a}, l\right)+r l_{c}=p z_{a}^{1-\gamma} l^{\gamma}+r\left(l_{c}-l\right) & \text { otherwise }\end{cases}
$$

Beyond labor income individuals earn rental income from communal land holdings $l_{c}$. Observe that non-agricultural workers $\left(\mathbb{1}_{a}=0\right)$ rent out all of their communal holdings while agricultural workers $\left(\mathbb{1}_{a}=1\right)$ either receive rental payments on land holdings that they do not operate $\left(l_{c}-l>0\right)$ or else rent in land over and above their holdings $\left(l_{c}-l \leq 0\right)$.

\subsection{Communal Land}

The economy's aggregate endowment of land is $L$. A fraction $\lambda \in[0,1]$ of it is communal, $L_{c}=\lambda L$, while the rest is strictly private, $L_{p}=(1-\lambda) L$. All communal land is held individually in the form of $l_{c}$, requiring $L_{c}=\int l_{c}(x) \mathrm{d} H(x)$. Within a time period, an individual has exclusive user rights over $l_{c}$, whether that be for the purpose of operation or out-rental. The sale of communal land, on the other hand, is not permitted. Frictions arise exclusively from the dynamics of individual communal land holdings that evolve through public interventions via expropriation and reallocation.

\subsubsection{Expropriation}

We assume that individual expropriation is governed by an exogenous institutional policy with the following key ingredients. Expropriation is defined as the loss of all

\footnotetext{
${ }^{19}$ In particular, we abstract from variable labor input. This is not a critical assumption given that the majority of agricultural hours worked across the world, both in developed and developing countries, are supplied by family members (Adamopoulos and Restuccia, 2014b). High monitoring costs are typically advanced as the reason why farms rarely expand in labor.
} 
current-period holdings $l_{c}$ at the start of the next period. Also, its occurrence is stochastic and subject to an endogenous hazard rate. What is critical is that the expropriation hazard rate depends on the individual's current-period actions. In particular, we make two crucial assumptions. First, individuals face no expropriation risk tomorrow as long as they operate at least the equivalent of their entire communal land holding today, $l \geq l_{c} \cdot{ }^{20}$ Second, whenever operations fall short of that level, $l<l_{c}$, the risk of expropriation is positive and the hazard rate is increasing in the fraction of communal land that is rented out $\left(l_{c}-l\right) / l_{c}$. The principle of "use it or lose it" applies. By renting out land that is not perfectly transferable, the individual runs the risk of losing it. The higher the fraction of rented out land, the stronger is the signal that the household does not require land for productive purposes. This enhances the motivation of the land authority to seize the farmer's holdings. Furthermore, our assumptions imply that the expropriation hazard is highest in the case of zero operations $(l=0)$, which coincides with the choice of employment in the non-agricultural sector. ${ }^{21}$

Formally, the expropriation hazard function is

$$
\pi_{E}\left(l_{c}, l\right)= \begin{cases}\tau\left(\frac{l_{c}-l}{l_{c}}\right)^{\mu} & \text { if } l_{c}-l>0 \\ 0 & \text { otherwise }\end{cases}
$$

The parameter $\tau \in[0,1]$ represents the highest possible expropriation hazard, which applies when $l=0$. The parameter $\mu \geq 0$ governs the curvature of the function with regard to the fraction of rented out land. The expropriation hazard is thus decreasing and convex in $l / l_{c}$, as illustrated in the left panel of Figure 2. The parameter $\mu$ spans various scenarios. When $\mu=1$ the expropriation hazard is linear in the fraction of rented out land. On the opposite end of the spectrum, when $\mu \rightarrow \infty$ the function tends

\footnotetext{
${ }^{20}$ Agents are assumed to operate their own holding $l_{c}$ before renting in any additional land.

${ }^{21}$ We take a short-cut by assuming that non-operated land is invariably rented out. Strictly speaking, the expropriation hazard is thought to increase in non-operated land so that renting it out rather than leaving it idle is always a dominant strategy. In Sub-Saharan Africa it is common practice for migrating farmers to leave their land for free in the hands of extended family members. In the context of our model, this is akin to expropriation as no rental payments are received.
} 
to zero as long as the individual's operations are strictly positive, $l>0$. In that case, farmers are completely shielded from expropriation, and the risk only applies to those leaving the farming sector altogether.

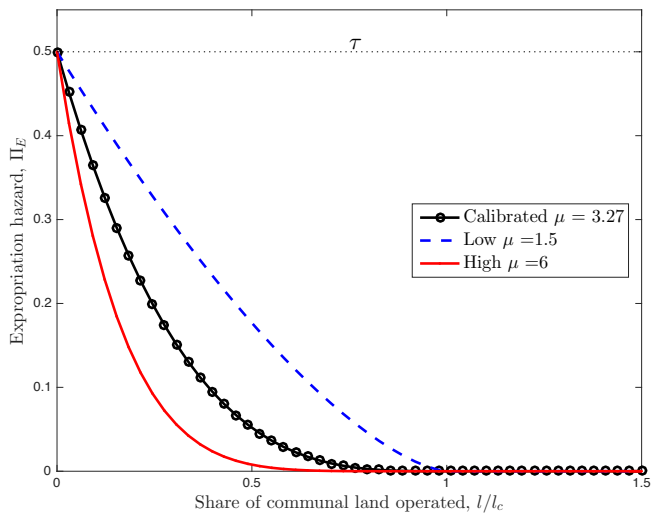

(a) Expropriation hazard function

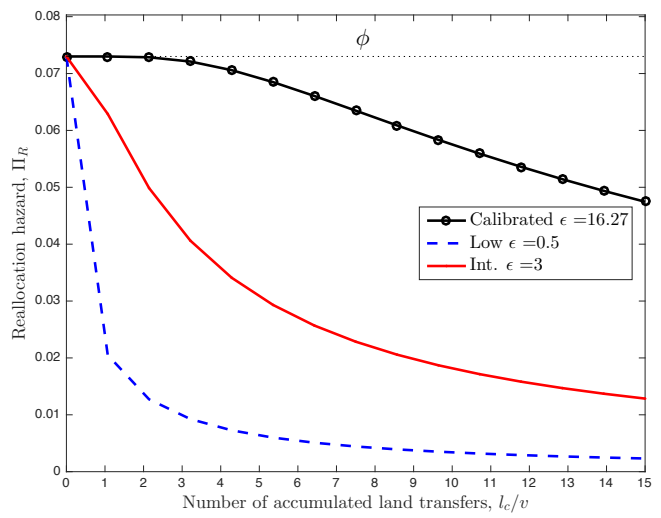

(b) Reallocation hazard function

Figure 2: Illustration of hazard functions

\subsubsection{Reallocation}

The second crucial piece in our institutional setup is the reallocation of expropriated land. Individuals can receive one lump-sum transfer $v$ in each period. That transfer is endogenous in size to ensure that the total of reallocated land equals the amount of expropriated land. Also, reallocation is stochastic, which is a suitable assumption: some individuals receive a better ex-post treatment by the local authorities than others. Finally, the hazard rate of receiving a transfer in the upcoming period is endogenous in the individual's current-period action and state. First, we assume that only currentperiod farmers are entitled to the transfer. Second, we assume that reallocation has a progressive element. The probability of an additional communal land transfers depends negatively on the amount of current communal land holdings $l_{c}$. 
Formally, the reallocation hazard function is defined as

$$
\pi_{R}\left(l_{c}, \mathbb{1}_{a}\right)= \begin{cases}\phi\left[1-\left(\frac{l_{c} / v}{1+l_{c} / v}\right)^{\epsilon}\right] & \text { if } \mathbb{1}_{a}=1 \\ 0 & \text { otherwise }\end{cases}
$$

The parameter $\phi \in(0,1]$ represents the highest possible probability of transfer receipt, which applies to landless farmers $\left(l_{c}=0\right)$. The degree of progressivity of the transfer function, meanwhile, is governed by $\epsilon>0$, as illustrated in the right panel of Figure 2. The lower is $\epsilon$, the lower is the likelihood of an additional transfer for any given strictly positive level of $l_{c}>0$. At $\epsilon \rightarrow 0$ only landless farmers can expect a transfer with probability $\phi$ while farmers with $l_{c}>0$ receive no additional land. Conversely, as $\epsilon \rightarrow \infty$ the transfer hazard equals $\phi$ for everyone and becomes independent of current holdings. In the stationary equilibrium, lump-sum transfers are identical across periods. Equilibrium holdings of communal land can then be expressed on a discrete grid $l_{c}=n v$, where $n \in \mathbb{N}$ is the individual's history of the number of accumulated transfers uninterrupted by expropriation.

\section{Characterization of the Equilibrium}

Henceforth we are interested in the stationary equilibrium as defined in the Appendix 9.2.1. Apart from the stationary distribution $H(x)$ this economy features three general equilibrium objects. Prices $p$ and $r$ clear the goods and land rental market, and the transfer value $v$ equates the amount of expropriated and redistributed land. 


\subsection{Individual Choices}

We begin by characterizing individual choices. For this it is convenient to write out the individual's value function in recursive form:

$$
\begin{aligned}
V\left(z_{a}, z_{n}, l_{c}\right)= & \max _{\mathbb{1}_{a}, l}\left\{\mathbb{1}_{a}\left(p z_{a}^{1-\gamma} l^{\gamma}-r l\right)+\left(1-\mathbb{1}_{a}\right) z_{n}+r l_{c}\right. \\
& +\beta\left[\left[1-\pi_{E}\left(l_{c}, l\right)\right] \pi_{R}\left(l_{c}, \mathbb{1}_{a}\right) \mathbb{E}_{z^{\prime} \mid z} V\left(z_{a}^{\prime}, z_{n}^{\prime}, l_{c}+v\right)\right. \\
& +\left[1-\pi_{E}\left(l_{c}, l\right)\right]\left[1-\pi_{R}\left(l_{c}, \mathbb{1}_{a}\right)\right] \mathbb{E}_{z^{\prime} \mid z} V\left(z_{a}^{\prime}, z_{n}^{\prime}, l_{c}\right) \\
& +\pi_{E}\left(l_{c}, l\right) \pi_{R}\left(l_{c}, \mathbb{1}_{a}\right) \mathbb{E}_{z^{\prime} \mid z} V\left(z_{a}^{\prime}, z_{n}^{\prime}, v\right) \\
& \left.\left.+\pi_{E}\left(l_{c}, l\right)\left[1-\pi_{R}\left(l_{c}, \mathbb{1}_{a}\right)\right] \mathbb{E}_{z^{\prime} \mid z} V\left(z_{a}^{\prime}, z_{n}^{\prime}, 0\right)\right]\right\}
\end{aligned}
$$

where $\mathbb{E}_{z^{\prime} \mid z} V\left(z_{a}^{\prime}, z_{n}^{\prime}, l_{c}^{\prime}\right)=(1-\zeta) V\left(z_{a}, z_{n}, l_{c}^{\prime}\right)+\zeta \int V\left(z_{a}^{\prime}, z_{n}^{\prime}, l_{c}^{\prime}\right) \mathrm{d} \Psi\left(z_{a}^{\prime}, z_{n}^{\prime}\right)$. The individual's continuation value depends on the size of future communal land holdings which hinge on today's actions. Communal land holdings can either rise by one transfer due to reallocation (second line of the value function, $l_{c}^{\prime}=l_{c}+v$ ); remain constant (third line, $l_{c}^{\prime}=l_{c}$ ); drop to zero due to expropriation and simultaneously increase by one transfer (fourth line, $l_{c}^{\prime}=v$ ); or drop to zero (fifth line, $l_{c}^{\prime}=0$ ).

\subsubsection{Efficient Economy}

The economy is efficient when the land rental market functions without restrictions. $^{22}$ Naturally, this occurs in the absence of communal land $(\lambda=0)$. However, even with $\lambda>0$ and agents detaining communal holdings, the economy is efficient as long as there exists no expropriation threat $(\tau=0)$. In that case there is no difference between communal and private land in the sense that property rights encompass both user and transfer rights. There is no threat of expropriation $\left(\pi_{E}=0\right)$ and no expectation of any further reallocation $\left(\pi_{R}=0\right)$ since no land is expropriated. Observe from the value function (3) that individual occupational decisions and land operations, then, only maximize period income as they have no bearing on the future.

\footnotetext{
${ }^{22}$ There is no need for a land sales market.
} 
Farmers equalize the marginal revenue of land operations to the rental rate,

$$
l^{\star}\left(z_{a} ; p, r\right)=\left(\frac{\gamma p}{r}\right)^{\frac{1}{1-\gamma}} z_{a}
$$

which gives the implied agricultural income:

$$
w_{a}^{\star}\left(z_{a} ; p, r\right)=\frac{1-\gamma}{\gamma}\left(\frac{\gamma p}{r}\right)^{\frac{1}{1-\gamma}} r z_{a}
$$

It is convenient to define two thresholds in the space of $z_{a}$. The first one is the threshold at which farmers' operations weakly exceed their own communal holdings, $l^{\star}\left(z_{a} ; p, r\right) \geq l_{c}$. Using (4) this condition is

$$
z_{a} \geq\left(\frac{r}{\gamma p}\right)^{\frac{1}{1-\gamma}} l_{c} \equiv K^{\star}\left(l_{c} ; p, r\right) .
$$

The second threshold of interest is that at which farming is an optimal choice $\left(\mathbb{1}_{a}=1\right)$, namely if and only if $w_{a}^{\star}\left(z_{a} ; p, r\right) \geq w_{n}\left(z_{n}\right)=z_{n}$. Using (5) this condition is

$$
z_{a} \geq \frac{\gamma}{1-\gamma}\left(\frac{r}{\gamma p}\right)^{\frac{1}{1-\gamma}} \frac{z_{n}}{r} \equiv T^{\star}\left(z_{n} ; p, r\right) .
$$

Thus, in the first-best equilibrium individuals become farmers if and only if $z_{a} \geq$ $T^{\star}\left(z_{n} ; p, r\right)$. Moreover, conditional on farming, they operate more than their holdings by renting in additional land if and only if $z_{a}>K^{\star}\left(l_{c} ; p, r\right)$. Conversely, farmers strictly rent out their communal holdings if and only if $z_{a}<K^{\star}\left(l_{c} ; p, r\right)$.

\subsubsection{Distorted Economy}

Next we turn to the distorted economy $(\tau>0, \lambda>0)$. In contrast to the efficient economy, individual choices are intertemporal. Our analysis distinguishes individuals by whether forward-looking behavior distorts their operational and occupational choices relative to the first-best. We define individuals as operationally constrained whenever optimal land operations depart from the first best, $l \neq l^{\star}\left(z_{a} ; p, r\right)$, i.e. the farmer's marginal revenue product does not equal the rental rate of land. Similarly, we define 
individuals as occupationally constrained if they choose farming despite being of type $z_{a}<T^{\star}\left(z_{n} ; p, r\right)$.

Proposition 1. Farmers of type $z_{a} \geq K^{\star}\left(l_{c} ; p, r\right)$ choose non-distorted land operations $l=l^{\star}\left(z_{a} ; p, r\right)$. Conversely, farmers of type $z_{a}<K^{\star}\left(l_{c} ; p, r\right)$ choose land operations such that $l^{\star}\left(z_{a} ; p, r\right)<l<l_{c}$.

Proof. See Appendix 9.2.2.

The threshold $K^{\star}$ in equation (6) is increasing in $l_{c}$. We therefore define farmers of type $z_{a} \geq K^{\star}\left(l_{c} ; p, r\right)$ as relatively land-poor. Their choice of operations does not affect their continuation value. They do not fear expropriation as they do not rent out land, and the probability of receiving land transfers is independent of operations l. Conversely, farmers of type $z_{a}<K^{\star}\left(l_{c} ; p, r\right)$ are defined as relatively land-rich as they prefer to rent out land. Doing so, however, raises the specter of expropriation. To protect themselves against such an outcome they rent out strictly less land than dictated by marginal productivity, which implies that they feature inefficiently high land operations.

Proposition 2. There exists a threshold $\bar{T}\left(z_{n}, l_{c} ; p, r, v\right)$ such that individuals become farmers $\left(\mathbb{1}_{a}=1\right)$ if and only if $z_{a} \geq \bar{T}\left(z_{n}, l_{c} ; p, r, v\right)$. In particular, $\bar{T}\left(z_{n}, l_{c} ; p, r, v\right)<$ $T^{\star}\left(z_{n} ; p, r\right)$.

Proof. See Appendix 9.2.3.

For individuals of type $z_{a} \geq T^{\star}\left(z_{n} ; p, r\right)$ agricultural employment dominates even in absence of any forward-looking considerations. We therefore define them as relatively skilled farmers and their occupational choice is not constrained. Now consider individuals such that $\bar{T}\left(z_{n}, l_{c} ; p, r, v\right)<z_{a} \leq T^{\star}\left(z_{n} ; p, r\right)$. Their comparative advantage is in non-agriculture yet these relatively unskilled farmers opt for the fresh air of the countryside over the glitz of the city. Their constrained occupational choice is motivated by two factors. The first is the risk of expropriation. The higher is the agent's communal holding $l_{c}$, the more he risks losing by choosing non-agriculture. The second 
motivation is the promise of an additional land transfer $v$ tomorrow. The higher is the transfer probability $\pi_{R}$ the more appealing is the agricultural activity.

\begin{tabular}{c|c|c}
\hline \hline & $z_{a} \geq K^{\star}\left(l_{c} ; p, r\right)$ & $z_{a}<K^{\star}\left(l_{c} ; p, r\right)$ \\
\hline$z_{a} \geq T^{\star}\left(z_{n} ; p, r\right)$ & Occupation: unconstrained & Occupation: unconstrained \\
& $\begin{array}{c}\text { Operation: unconstrained } \\
l=l^{\star}\left(z_{a} ; p, r\right) \geq l_{c}\end{array}$ & $\begin{array}{c}\text { Operation: constrained } \\
l \in\left(l^{\star}\left(z_{a} ; p, r\right), l_{c}\right)\end{array}$ \\
\hline $\bar{T}\left(z_{n}, l_{c} ; p, r, v\right)$ & Occupation: constrained & Occupation: constrained \\
$\leq z_{a}<$ \\
$T^{\star}\left(z_{n} ; p, r\right)$ & Operation: unconstrained & $\begin{array}{c}\text { Operation: constrained } \\
l \in\left(l^{\star}\left(z_{a} ; p, r\right), l_{c}\right)\end{array}$ \\
\hline
\end{tabular}

Table 1: Characterization of farmer types

We characterize four groups of farmers, as summarized in Table 1. First, relatively skilled and land-poor farmers $z_{a} \geq \max \left\{T^{\star}, K^{\star}\right\}$ are operationally and occupationally unconstrained. These can be understood as a metaphor for young farmers with little land at their disposal who are either exceptionally skilled in farming or else display limited talent for non-agricultural activities. The presence of the land policy regime does not affect their choices. Second, relatively skilled and land-rich farmers $T^{\star} \leq z_{a}<$ $K^{\star}$ are unconstrained in their occupational choice yet run excessive land operations. Vis-à-vis the first group they could be pictured as older, having accumulated relatively large land holdings. They rent out a fraction of their holdings and would rent out even more if it was not for the threat of expropriation. Their comparative advantage, though, is in farming; for instance because their non-agricultural skills are extremely low. Third, relatively unskilled and land-poor farmers $\max \left\{\bar{T}, K^{\star}\right\} \leq z_{a}<T^{\star}$ are occupationally constrained yet choose non-distorted land operations. We can think of them as young farmers with relatively little land and a comparatively high outside option in nonagricultural activities. If they choose to be farmers it is because their non-agricultural skills are not sufficiently dominant to outweigh both the threat of losing their existing plots and the expectation of future land transfers. Finally, relatively unskilled and land-rich farmers $\bar{T} \leq z_{a}<\max \left\{T^{\star}, K^{\star}\right\}$ are constrained in both occupation and operations. They are exemplified by farmers with exceptionally large land holdings 
and a comparative advantage in non-agriculture. If they remain in agriculture it is primarily because they fear expropriation.

\subsection{General Equilibrium Forces}

Proposition 2.2 states that at any given prices $p$ and $r$ the threshold for entering agriculture is always lower than in the first-best, $\underline{T}\left(z_{n}, l_{c} ; p, r, v\right)<\bar{T}\left(z_{n} ; p, r\right)$. Distortions tend to pull more individuals into farming, which increases demand for land. In addition, some farmers (the relatively land-rich ones) are encouraged to overproduce via excessive land operations. In equilibrium these forces exert an upward pressure on the rental rate $r$, both due to an increase in demand and a fall in supply on the rental market. Also, the additional production of agricultural output leads to downward pressure on its price $p$.

What is the consequence of these price effects? Some potential farmers are discouraged from entering agriculture. These are typically those with little communal land $l_{c}$ who must cope with high land rents, and those with a relatively high outside option in non-agriculture, $z_{n}$. When agricultural and non-agricultural skills are positively correlated, such agents may well be highly skilled potential farmers. This highlights that while the communal regime in partial equilibrium tends to attract more individuals into the farming sector, ultimately some individuals are pushed in the other direction. It is therefore not obvious whether in equilibrium we end up with relatively high or low agricultural output and whether the price of the agricultural good is likely to be lower or higher than in the first-best. We loosely juxtapose two potential scenarios to

distinguish between general equilibrium outcomes in the communal regime as opposed to the first-best.

In the first scenario the additional individuals drawn into agriculture in the communal regime are relatively skilled farmers. Operational distortions are low, either because communal land is held predominantly by relatively skilled farmers or because the rental market for communal land remains sufficiently active. The economy pushes towards excess production of agricultural output so that its price $p$ drops steeply. This 
limits the number of interested farmers and the aggregate effect on occupation is limited. The second scenario is one where the influx of farmers creates large distortions in land operations because farmers are loath to rent out land. Agricultural production therefore does not rise much in relative terms, and may even fall. As a result, the agricultural price $p$ does not drop strongly or may even increase. Lacking a strong countervailing general equilibrium force, the economy exhibits a large mass of farmers compared to the first-best.

\section{Calibration}

We proceed to the calibration of the model, based on data from Ethiopia around the year 2012. As described in subsection 2.2, the tenure regime in Ethiopia facilitates the mapping to the data. First, Ethiopia has explicit laws that are represented in our expropriation and reallocation functions. Second, the tenure regime has remained stable for about three decades prior to 2012, which implies a time frame that is sufficiently long to compare empirical outcomes to a stationary distribution. Third, because land sales are forbidden, the current land distribution can be rationalized as a result of the

proposed policies. Fourth, since all land is communal, we do not need to worry about any potential co-variation between the distributions of communal and private land.

The calibration strategy is summarized in Table 2. A number of parameters are set, the remaining ones (grouped under skills, preferences, and policy) are jointly calibrated.

\subsection{Set Parameters}

Since all land in Ethiopia is communal we set $\lambda=1$. Based on the legal provisions outlined in the previous subsection, we posit that the entire land holding can be rented out following migration, but that expropriation kicks in on average after two years. This strikes a balance between the principle that non-farmers cannot rent out land at all, and the fact that in practice land rentals are not immediately detected. We thus fix the maximum expropriation hazard $\tau$ to 0.5 .

The land endowment $L$ is normalized to unity. As the model is calibrated to annual frequency we fix the discount factor $\beta$ to 0.96 , a standard time discount factor used 


\begin{tabular}{lcll}
\hline \hline \multicolumn{1}{c}{ Parameter } & Value & Target \\
\hline Set parameters & & & \\
\hline Share of communal land $(\lambda)$ & 1.00 & Normalization \\
Max. expropriation hazard $(\tau)$ & 0.50 & Ethiopian law & \\
Endowment of land $(L)$ & 1.00 & Normalization & \\
Discount factor $(\beta)$ & 0.96 & Annual frequency & \\
Probability to draw new skill set $(\zeta)$ & 0.02 & Frequency of talent draw & 0.831 \\
Span of control $(\gamma)$ & 0.33 & Land share & 0.630 \\
\hline Calibrated parameters & & & 3.636 \\
Talent distribution non-agriculture $\left(\psi_{n}\right)$ & 1.454 & Variance of non-ag. wages $(\log )$ & 0.727 \\
Talent distribution agriculture $\left(\psi_{a}\right)$ & 1.592 & Variance of land to labor ratio $(\log )$ & 0.330 \\
Interdependence $(\rho)$ & 1.465 & Labor income non-ag. vs ag. & 0.195 \\
Subsistence requirement $(\bar{a})$ & 0.821 & Agricultural employment share & 0.069 \\
Relative preference for ag. goods $(\eta)$ & 0.444 & GDP share of subsistence cons. \\
Curvature of expropriation function $(\mu)$ & 3.270 & Share of land rented in & 0.006 \\
Probability to obtain a land transfer $(\phi)$ & 0.073 & Fraction of landless farmers & \\
Progressivity of land redistribution $(\epsilon)$ & 16.267 & Expropriation rate & \\
\hline
\end{tabular}

Table 2: Calibration

in frictionless environments to generate an interest rate of 4 percent. We also fix the hazard rate of skill change $\zeta$ to 0.02 . This implies that the entire set of individualspecific skills changes on average once in 50 years, or roughly once in a generation. Such a choice represents a middle ground between recognizing that the within-generational auto-correlation is not perfect (calling for a higher $\zeta$ ) and the fact that the crossgenerational auto-correlation is likely to be positive (demanding a lower $\zeta$ ). The land intensity parameter $\gamma$ is set to 0.33 . In absence of frictions, this parameter is equivalent to the agricultural land share. Historically, share-cropping arrangements have assigned by rule-of-thumb a value of between $1 / 3$ and $1 / 2$ to landowners as reported e.g. in Mundlak (2005). We settle for the more conservative lower bound in the light of evidence that the land share in modern agriculture may be somewhat lower than onethird..$^{23}$

\footnotetext{
${ }^{23}$ For the U.S. Valentinyi and Herrendorf (2008) find that the income share accruing to land in agricultural value-added is a fraction $0.18 /(0.18+0.64)=0.28$ of the combined labor and land shares. Such a relatively low land share results from the imputation of the indirect contribution of land from non-agricultural intermediate inputs for which land is negligible. However, the nominal agricultural intermediate input share in Sub-Saharan Africa is low relative to developed economies (Donovan, 2016), suggesting that more weight should be attached to the direct contribution of land. Setting $\gamma=0.33$ therefore appears to be a reasonable middle ground.
} 


\subsection{Skills}

Following Lagakos and Waugh (2013) we assume that the skill distribution $\Psi\left(z_{a}, z_{n}\right)$ is represented by a Frank copula $\Psi\left(z_{a}, z_{n}\right)=F\left[\Psi_{a}\left(z_{a}\right), \Psi_{a}\left(z_{a}\right)\right]$ of the individual Fréchet

distributions $\Psi_{a}\left(z_{a}\right)=\exp \left(z_{a}^{-\psi_{a}}\right)$ and $\Psi_{n}\left(z_{n}\right)=\exp \left(z_{n}^{-\psi_{n}}\right)$. The parameters $\psi_{a} \geq 0$ and $\psi_{n} \geq 0$, respectively, determine both the mean and the dispersion of talent in each sector. The copula parameter $\rho$ governs the interdependence of the draws, ranging from perfectly negative interdependence $(-\infty)$ via independence $(0)$ to perfectly positive interdependence $(\infty)$.

The empirical data moment chosen to discipline $\psi_{n}$ is the variance of the permanent component of $(\log )$ earnings in the non-agricultural sector. We compute this to be 0.831 from the LSMS-ISA panel dataset for Ethiopia. The associated calibrated value of $\psi_{n}$ is 1.454. For agriculture we set $\psi_{a}$ so that our model matches the empirical variance of the permanent component of the $(\log )$ ratio between operated land and labor at the household level. In particular, we focus on a restricted sample of GPS measured pure-stand fields on which staple crops are planted for the two waves of the LSMS-ISA survey. We estimate the permanent component of the agricultural land to labor ratio by regressing our measure on household and time fixed effects. The empirical variance is 0.63 and the associated calibrated value of $\psi_{a}$ equals 1.592. Please see Appendix 9.3.1 for further details.

Similarly to Lagakos and Waugh (2013) the interdependence parameter of the skill draws $\rho$ is calibrated to match the average nominal labor productivity in the nonagricultural sector relative to that in the agricultural sector, $\left(Y_{n} / N_{n}\right) /\left(p_{a} Y_{a} / N_{a}\right)$, with labor shares $N_{a}=\int \mathbb{I}_{a}(x) \mathrm{d} x$ and $N_{n}=1-N_{a}$. Empirically, this ratio is calculated as

$$
\frac{Y_{n} / N_{n}}{p_{a} Y_{a} / N_{a}}=\frac{\left(1-\alpha_{n}\right)\left(1-V A_{a}\right) / N_{n}}{\left(1-\alpha_{a}\right) V A_{a} /\left(1-N_{a}\right)}
$$

where $V A_{a}$ refers to the agricultural sectoral value-added share and $\alpha_{i}$ is the sum of sectoral capital and land income shares for each sector $i=\{a, n\}$. Put differently, we compute the capital-adjusted nominal APG. Using World Bank data, the 2012 values 
for Ethiopia are $N_{a}=0.727$ and $V A_{a}=0.449$. In absence of precise data on aggregate income shares we fix $\alpha_{n}$ to the standard value 0.33 while for agriculture we choose $\alpha_{a}=0.43$ which is the sum of the land share (0.33) and an assumed physical capital share of 0.1 . This results in a target moment of 3.636. The calibrated parameter $\rho$ takes the value 1.465. It produces a correlation coefficient between $\log z_{a}$ and $\log z_{n}$ of 0.47 , and a Spearman rank correlation of 0.44 . We cannot check for the validity of such a correlation, but it appears reasonable. While skills in the two activities ought to positively correlated (through a common component of cognitive and physical ability), they are far from identical as they comprise different tasks and are acquired through different experiences.

\subsection{Preferences}

The subsistence requirement $\bar{a}$ is calibrated to 0.821 in order to match a share of aggregate income spent on subsistence consumption $p_{a} \bar{a} /\left(p_{a} Y_{a}+Y_{n}\right)$ of 0.33 . This is an estimate from Rosenzweig and Wolpin (1993) on a sample of Indian rural households in 1984. We use it based on the fact that GDP per capita in India in 1984 is comparable to that of Ethiopia in 2012. ${ }^{24}$ We follow the literature by also targeting the fraction of agricultural employment, $N_{a}=0.727$. The corresponding preference parameter for agricultural goods $\eta$ is thus calibrated to 0.444 .

\subsection{Policy}

This leaves us with three remaining policy parameters. The first moment is the fraction of rented out communal land, $\left(\int \max \left\{l_{c}(x)-l(x), 0\right\} \mathrm{d} x\right) / L_{c}$. We compute this to be $19.5 \%$ as a simple average between the 2011-2012 and 2013-2014 LSMS-ISA rounds. The rental market in Ethiopia is active as reflected in the calibrated value of the parameter $\mu$ that governs the curvature of the expropriation hazard function. At 3.270 the quantification suggests that while farmers who rent out land are not shielded from expropriation (as $\mu<<\infty$ ), they do run a considerably lower risk than migrants (as

\footnotetext{
${ }^{24}$ Following World Bank data, GDP per capita in constant 2005 dollars (the only comparable data series) amounts to 325 USD for India in 1984 and 272 USD for Ethiopia in 2012.
} 
$\mu>1$ ). For instance, when renting out half of their holding, the expropriation hazard is only about 5 instead of 50 percent. Another data moment that we obtain from the LSMS-ISA is the fraction of landless farming households, which is $6.9 \%$ (computed as the fraction of farmers who rent in their entire land operations). The parameter that exerts the strongest influence on that outcome is $\phi$, the probability faced by landless farmers of being allocated communal land, calibrated to 0.073. This implies that a landless farming household needs to wait on average about 14 years to be allocated a plot of communal land.

The last remaining policy parameter, $\epsilon$, determines the progressivity of the reallocation hazard function. It is tightly linked to other matched moments described above, such as the variability of operations and the fraction of rented out land. At the same time it also generates the allocation of communal holdings and therefore governs the degree of potential mismatch between individual holdings and marginal productivities. As such it is indirectly related to the equilibrium expropriation rate, namely the fraction of individuals that in a given period experience expropriation. Because there are no recent comprehensive data on expropriation, we rely on our own small-scale household questionnaire administered in several distinct locations in Ethiopia (please see Appendix 9.3.2 for details). In particular, we inquired whether the household or the parents of the household's head have ever been subject to land expropriation. From this we compute an expropriation rate of $0.55 \%$. Put into perspective, this implies that each year one in two hundred households experiences expropriation. ${ }^{25}$ The calibrated value of the parameter $\epsilon$ is 16.23 , which is high. It suggests that the probability of being allocation communal land (conditional on farming) is almost independent of the size

\footnotetext{
${ }^{25}$ Admittedly, this figure is imprecisely estimated as our sample of 44 households is small. At the same time, it is likely to be a conservative lower bound. Based on a nationally representative survey of farm households, Deininger and Jin (2006) find that 9 percent of farmers were affected by land redistribution in the period between 1991 and 1998. Also, the dataset used in Dercon and Krishnan (2010) confirms that about 7 percent of household lost land during the redistribution between 1994 and 1999. These frequent expropriations, however, also include episodes of land redistributions in the 1990s that differ from the expropriation mechanism proposed in our model. For this reason we settle on a relatively low rate of expropriation.
} 
of existing land holdings. ${ }^{26}$ This is consistent with the empirical evidence presented in subsection 2.2 .

\subsection{Non-Targeted Moments}

We evaluate the performance of our model by highlighting a number of important non-targeted moments. First, the model generates a variance of $(\log )$ agricultural skills $z_{a}$ of 0.97 among the individuals employed in agriculture. The empirical counterpart, which is backed out from our production technology (see subsection 9.3.1 for details) is computed to be 1.23. Second, the model predicts a variance of (log) communal land holdings $l_{c}$ of 0.57 . In comparison, the empirical measure is 0.61 . While the model understates the dispersion of operations and holdings relative to the data, the discrepancies are not large. In addition, we note that the model matches the empirics qualitatively by producing a slightly lower dispersion in holdings than in operations. Third, the correlation between land holdings and operations in the model is 0.79. In the data that correlation amounts to 0.75 on average across the two LSMS-ISA waves. This gives us confidence that our model captures well the frictions in the rental market that produce a high correlation between holdings and operations.

\section{Main Results}

In the following Section we use the model to measure the impact of communal land on the stationary equilibrium. We compare economies with different fractions of communal land, $\lambda$, while keeping all other parameters constant. The most immediate comparison is that of our calibrated Ethiopian economy $(\lambda=1)$ to its counterfactual featuring no communal land at all $(\lambda=0)$. We first evaluate the impact of communal land on individual choices before assessing how these choices pan out in aggregate statistics.

\footnotetext{
${ }^{26}$ For example, if the probability of passing from no land to a first transfer is $\phi$, the probability of passing from nine to ten transfers is $0.82 \times \phi$.
} 


\subsection{Individual Choices}

How does communal land impact occupational choices? The left panel of Figure 3 depicts the average agricultural employment rate as a function of agricultural skill. ${ }^{27}$ In the non-distorted economy $(\lambda=0)$ agricultural employment is increasing in $z_{a}$. Now consider the relationship in the presence of communal land. The institution lures disproportionately many low-skilled agricultural workers into farming. In an economy without communal land, individuals with the least agricultural talent do not select into farming, whereas in our benchmark economy $(\lambda=1)$ one third of them do. The communal tenure regime waters down the correlation between agricultural talent and agricultural employment. The correlation between $\log z_{a}$ and $\mathbb{I}_{a}$ declines from 0.36 at the first-best to 0.21 in the benchmark economy (see Table 3).

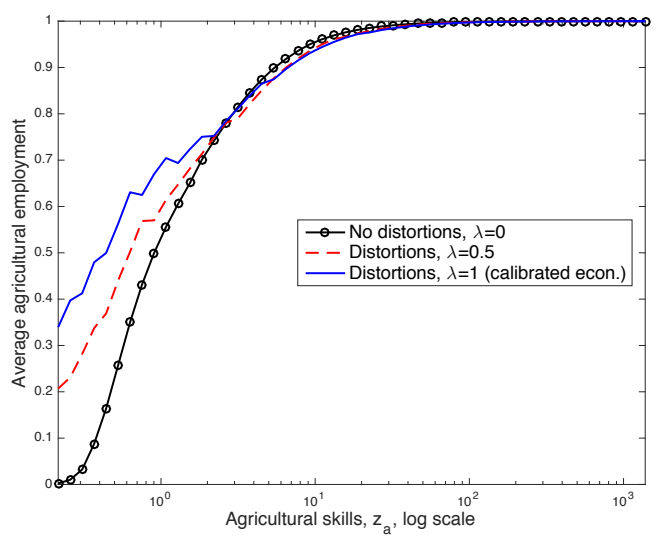

(a) Average agr. employment

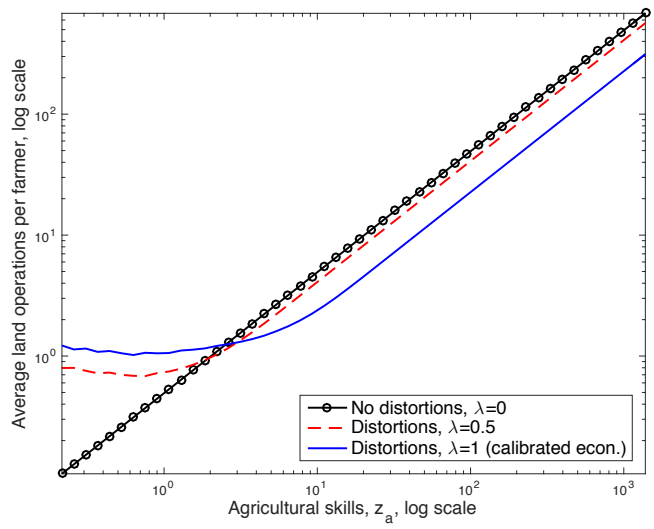

(b) Average land operations of farmers

Figure 3: Agr. employment and operations by agr. skills.

Next, consider average agricultural employment as a function of individual communal land holdings, portrayed in the left panel of Figure 4. At $\lambda=0$ there is no communal land so we only plot average aggregate agricultural employment. ${ }^{28}$ In each of the distorted equilibria, on the other hand, access to communal land strongly affects

\footnotetext{
${ }^{27}$ That is the mean, for each skill $z_{a}$, over the corresponding mass of types $z_{n}$ and $l_{c}$.

${ }^{28}$ Remember, however, that even if individuals owned communal land but faced no expropriation $(\tau=0)$, operations would be independent of holdings.
} 
sectoral selection: average employment in the agricultural sector is close to 1 for individuals holding at least one unit of communal land. There are two forces that underlie the strong correlation between agricultural employment and communal holdings. On the one hand, individuals with a comparative advantage in farming sort into that sector and, eventually, obtain communal land through redistribution. On the other hand we have the distortionary pull force. Some individuals select into the farming sector precisely because they hope to obtain land transfers. And, once they accumulate any strictly positive amount of land they remain "locked into" the agricultural activity as they are unwilling to risk losing land by switching sectors. This holds particularly for individuals whose skill set changes. Such agents accumulated holdings during periods when they had a comparative advantage in agriculture, but due to a change in skills they may now pursue an activity in which they lack comparative advantage. Furthermore, note from Table 3 that conditioning on strictly positive holding, $l_{c}>0$, the correlation between $\log l_{c}$ and the decision to be active in agriculture is weakly positive. A good predictor of whether individual are active in agriculture is whether they detain any communal land, rather than how much.

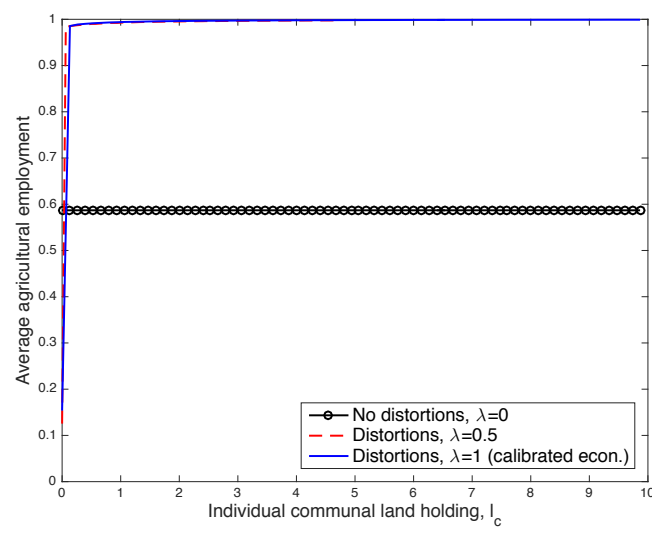

(a) Average agr. employment

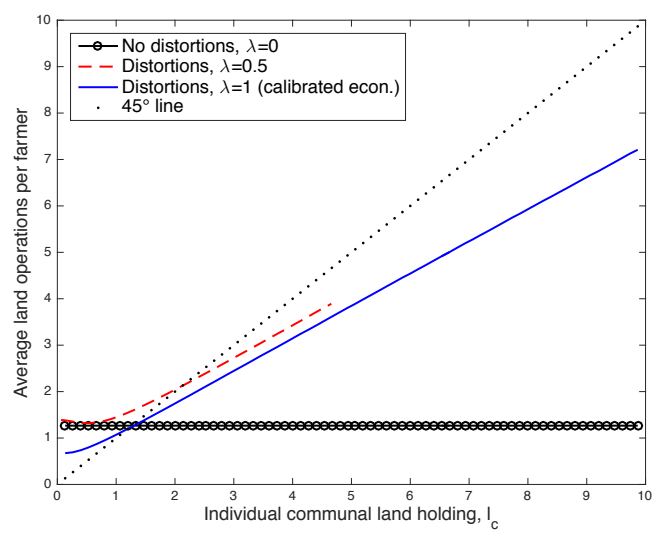

(b) Average land operations

Figure 4: Agr. employment and operations by land holdings.

How does communal land impact operational choices? The right panel of Figure 3 plots average land operations of farmers as a function of agricultural skills. In the 
non-distorted economy individual farmer operations (in logs) are linear in agricultural skills (in logs), with a slope coefficient of one. In the distorted economy, that is also approximately true for the very high skilled farmers. Only a tiny fraction of them own communal holdings that exceed their operations, so an overwhelming majority equalize their marginal product with the rental rate. The reason why their operations are lower than in the non-distorted economy is that the effective rental rate $r / p$ is higher. For low-skilled agricultural workers, on the other hand, the relationship between average land operations and skills breaks down. On average they operate substantially more land than they otherwise would in absence of the policy distortion. In fact, we observe that the relationship between average land operations and $z_{a}$ is not even monotonic. This is due to selection. The very least skilled agricultural workers are only present in that sector because they detain relatively large land holdings. While the correlation between $\log z_{a}$ and $\log l$ is perfect at the first-best, it falls to 0.47 in the benchmark economy (Table 3).

\begin{tabular}{lccc}
\hline \hline & \multicolumn{3}{c}{ Share of communal land } \\
& $\lambda=0$ & $\lambda=0.5$ & $\lambda=1$ \\
\hline $\operatorname{corr}\left(\log z_{a}, \mathbb{I}_{a}\right)$ & 0.36 & 0.27 & 0.21 \\
$\operatorname{corr}\left(\log z_{a}, \log l\right)$ & 1.00 & 0.84 & 0.47 \\
$\operatorname{var}\left(\log z_{a}\right)$ & 0.71 & 0.72 & 0.71 \\
$\operatorname{var}(\log l)$ & 0.71 & 0.54 & 0.63 \\
$\operatorname{corr}\left(\log l_{c}, \mathbb{I}_{a}\right)$ & - & 0.04 & 0.04 \\
$\operatorname{corr}\left(\log l_{c}, \log l\right)$ & - & 0.30 & 0.79 \\
$\operatorname{var}\left(\log l_{c}\right)$ & - & 0.59 & 0.57 \\
\hline
\end{tabular}

Table 3: Dispersion and correlation across equilibria

That can also be observed from the right panel of Figure 4. Conditioning on agricultural employment, individuals' scale of operation is increasing in communal holdings. First, individuals who own land are more likely to be better farmers: because the skill set changes slowly the stock of communal land holders is disproportionately drawn from previously and hence persistently talented farmers. Second, individuals overproduce to reduce the threat of expropriation. Conditional on detaining strictly positive holdings, $l_{c}>0$, the correlation between $\log l_{c}$ and $\log l$ is strong, 0.79 (Table 3 ). 


\subsection{Aggregate Statistics}

We now turn to the central result of this paper, the impact of communal land tenure on aggregate statistics. The crucial comparison is that between our calibrated economy $(\lambda=1)$ and a non-distorted one $(\lambda=0)$. We also report intermediate cases of $\lambda$, which are suggestive of economies with similar characteristics to Ethiopia's but where communal land coexists with fully private land.
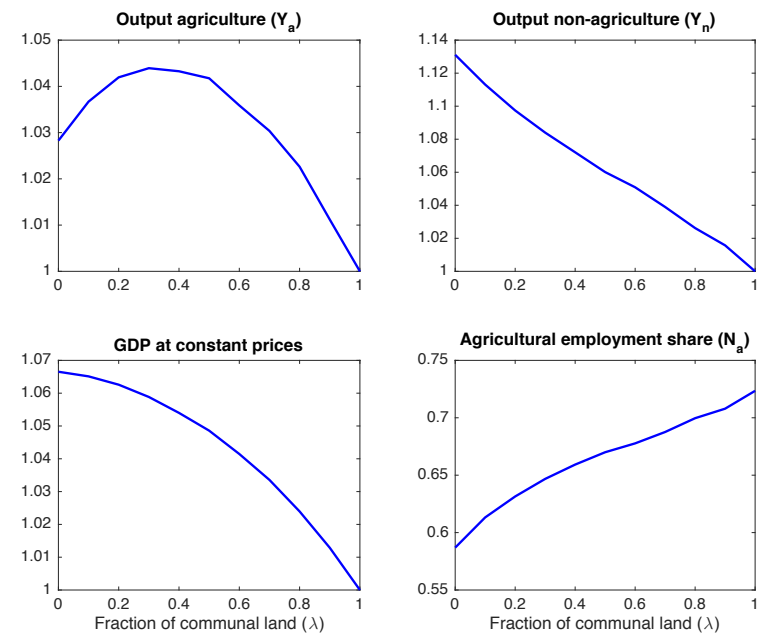

Figure 5: Real aggregates (all variables except employment normalized to calibrated economy, $\lambda=1$ )

Figure 5 plots how real aggregates move across stationary equilibria as we reduce the share of communal land $(\lambda)$, from right to left. Our calculations suggest that if a country such as Ethiopia were to liberalize land transfers completely, GDP would increase by almost $7 \%{ }^{29}$ That rise is mostly driven by an increase of $13 \%$ in nonagricultural output, driven by higher employment in that sector. We find that land liberalization is associated with a sizeable drop in the share of farmers of about 14 percentage points (i.e., a 19\% reduction in agricultural employment and a $46 \%$ increase in non-agricultural employment).

All these movements are monotonic and quite linear in $\lambda$. The exception is agricultural output. Fully transferable land leads to slightly more agricultural output than the

\footnotetext{
${ }^{29} \mathrm{GDP}$ is evaluated in constant prices of the calibrated economy, $Y_{n}+p_{\lambda=1} Y_{a}$. None of the following results changes significantly if the constant price is the non-distorted one $\left(p_{\lambda=0}\right)$.
} 
current regime, up by some 3 percent. The point at which agricultural output peaks, however, is at around $\lambda=0.3$. Why? There exist two offsetting equilibrium forces. Communal land distorts land operations and thus lowers agricultural output. Simultaneously it distorts employment decisions towards agriculture, which raises agricultural output. In an economy where most of the land is communal, many talented farmers operate significantly below potential because little land is rented out and rental rates are high. Introducing a little bit of private land has an important impact on that margin, leading to higher agricultural output. In contrast, in economies where a sizable fraction of land is private, operational distortions play second fiddle - any further reduction in communal land produces few gains in operational allocation. As for the improvement in occupational misallocation, it occurs over the whole institutional space. A decrease in $\lambda$ is in fact associated with a stronger drop in agricultural employment in economies with little private land (in levels, as depicted, and even more so in relative terms). Put differently, even economies with little aggregate communal land feature quite a lot of occupational misallocation by incentivizing a sizable fraction of low skilled individuals to work in farming.
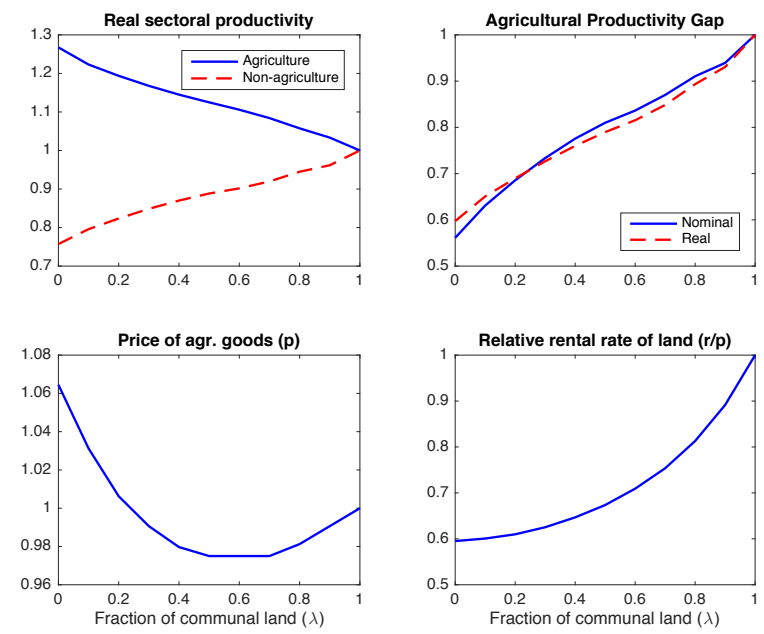

Figure 6: Productivity and prices (all variables normalized to calibrated economy, $\lambda=1$ )

Our second main concern in this paper is the impact of communal land on sectoral productivity measures. The upper left panel of Figure 6 reports that land liberal- 
ization is associated with a steady rise in real agricultural productivity $Y_{a} / N_{a}$ and a steady decline in real non-agricultural productivity $Y_{n} / N_{n}$. Agricultural productivity is pushed up both as a consequence of improved land allocation across users and because of a compositional change in the agricultural workforce: the average farmer quality increases as more land becomes private. The drop in non-agricultural productivity, meanwhile, is due entirely to the compositional change of non-agricultural workers. Altogether, the upper right panel indicates that the real agricultural productivity gap, $\left(Y_{n} / N_{n}\right) /\left(Y_{a} / N_{a}\right)$, plummets by $40 \%$ as a result of full land liberalization. Lifting the communal land regime in an economy such as Ethiopia thus substantially reduces the real APG puzzle.

Furthermore, the nominal APG, $\left(Y_{n} / N_{n}\right) /\left(p Y_{a} / N_{a}\right)$, moves in tandem with its real counterpart because the agricultural price $p$ remains quite stable. Full land liberalization results in a drop of $44 \%$; communal land therefore serves as a major explanatory variable for the nominal APG puzzle. Why? Because the associated decrease in real non-agricultural productivity relative to agriculture is not counteracted by a commensurate drop in the price of agricultural output. In fact, we note that the price $p$ is non-monotonically related to the fraction of communal land $\lambda$. This speaks again to the relative importance of occupational as opposed to operational distortions. At high values of $\lambda$ the introduction of private land induces a first-order impact on improved land operations that increases food production and hence lowers its price. At lower values of $\lambda$ a further liberalization of land reduces agricultural output and hence pushes up $p .{ }^{30}$ The relative price of agricultural output can therefore be understood as a proxy measure for the relative importance of occupational versus operational misallocation. Given that it is higher in the benchmark economy than in the first-best, we conclude that occupational misallocation plays a comparatively stronger role. Finally, notice that land liberalization induces a steep decline in the relative cost of land, $r / p$.

Additional variables of interest are summarized in Figure 7. The first panel plots

\footnotetext{
${ }^{30}$ In addition, due to the subsistence term in preferences, the income elasticity of agricultural goods declines as $\lambda$ decreases.
} 

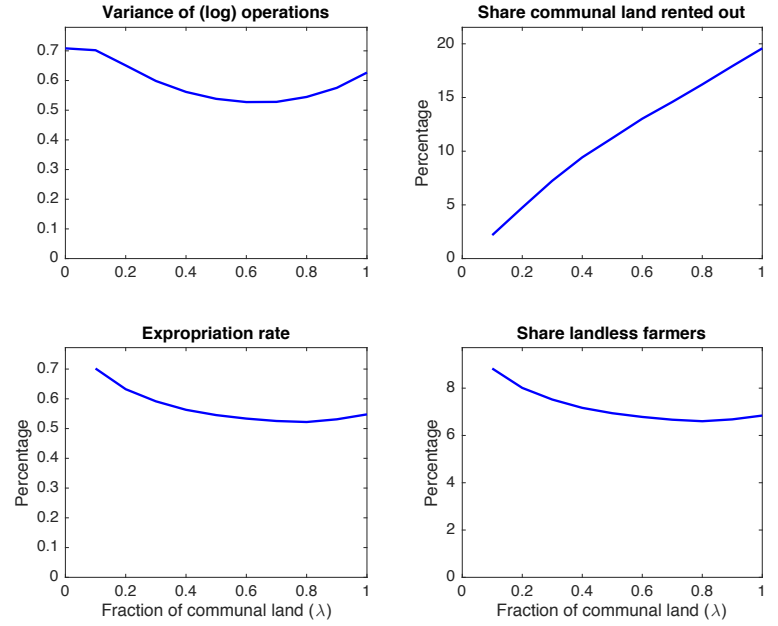

Figure 7: Land allocation

the variance of $(\log )$ land operations across the institutional space. We find that lifting transfer restrictions increases dispersion. The change is minor with respect to the benchmark economy, and more pronounced compared to economies where communal and private land coexist. Limited transferability therefore helps in explaining the low dispersion of farm size in developing countries, as identified for example by Adamopoulos and Restuccia (2014b). The U-shape can be explained by the following decomposition of $\operatorname{var}(\log l)$. Let $l(x)=d(x) \times l^{\star}\left(z_{a}\right)$ where $d(x) \geq 1$ indicates the degree of operational distortions (i.e., at the first-best $d(x)=1$ ). Since $l^{\star}$ is linear in $z_{a}$, we have $\operatorname{var}(\log l)=\operatorname{var}\left(\log z_{a}\right)+\operatorname{var}(\log d)+2 \times \operatorname{cov}\left(\log z_{a}, \log d\right)$. It turns out that the variance of $\log z_{a}$ is almost flat in $\lambda$, it therefore has little impact on the dispersion of operations. When $\lambda$ is reduced, there are two remaining and opposing forces at work. First, operational distortions decline, leading to a drop in $\operatorname{var}(\log d)$. Second, distortions become less strongly associated with low-skilled farmers, which reduces (in absolute value) the negative covariance term. In an economy where most land is communal (high $\lambda$ ), the first effect dominates, leading to a decline in the dispersion of operations. At lower values of $\lambda$ these forces are reversed.

Next, as depicted in the upper right panel of Figure 7, the fraction of rented out communal land is lower in regimes with less communal land. In such economies indi- 
viduals detain lower communal plots which are therefore less likely to exceed efficient operations. Accordingly, fewer individuals rent them out. What is surprising, then, is that the effective expropriation rate - defined as the fraction of land holders that are expropriated in each period - is somewhat higher in economies where less land is communal (lower left panel). That results from a composition effect. The aggregate expropriation rate can be decomposed as $e=e_{a} m_{a}+e_{n}\left(1-m_{a}\right)$ where $e_{a}$ and $e_{n}$ are the expropriation rates of agricultural and non-agricultural workers, respectively, and $m_{a}$ is the relative share of communal land holders who are active in agriculture. At $\lambda=1$ the expropriation rate is accounted for in about equal measure by farmers $(44 \%)$ and non-farmers (56\%). Farmers represent the bulk of communal land holders $\left(m_{a}=0.994\right)$. Their expropriation rate $\left(e_{a}=0.24 \%\right)$, though, is orders of magnitude lower than that of non-farmers (i.e., $e_{n}=50 \%$ is constant, equal to $\tau$ ). As $\lambda$ decreases, the expropriation rate of farmers $e_{a}$ declines further as less land is rented out. This, however, is counteracted by a more than proportional rise in the share of non-agricultural land holders $\left(m_{a}\right.$ falls). ${ }^{31}$ Finally, the share of landless farmers (lower left panel) moves in tandem with the aggregate expropriation rate.

\section{Quantitative Experiments}

\subsection{Securing Transfer Rights and Occupational Switch}

Suppose that an economy such as Ethiopia were to make an unannounced reform that permanently secured property rights by suspending the threat of expropriation (i.e., by setting $\tau=0$ ). Our model economy would immediately jump to an efficient equilibrium with individuals being heterogeneous in endowments $l_{c} \cdot{ }^{32} \mathrm{In}$ this subsection we quantify the mass of individuals based on their initial characteristics. We then separate them according to whether or not they switch sectors as a result of the reform.

\footnotetext{
${ }^{31}$ For example, at $\lambda=0.1$ almost no farmer experiences expropriation $\left(e_{a}=0.001 \%\right)$ while $m_{a}=$ 0.986. Here, expropriation is effectively only associated with non-agricultural workers.

${ }^{32}$ There is no transition period as expropriation and redistribution stop at once.
} 


\begin{tabular}{|c|c|c|c|c|c|c|c|c|c|c|}
\hline \multirow{3}{*}{$\begin{array}{l}\text { Occupation, } \bar{T} \\
\text { Occ. constraint, } T^{\star} \\
\text { Oper. constraint, } K^{\star}\end{array}$} & \multicolumn{9}{|c|}{ Farmers } & \multirow{3}{*}{$\begin{array}{c}\text { Non-farmers } \\
- \\
-\end{array}$} \\
\hline & \multicolumn{3}{|c|}{ No } & \multicolumn{3}{|c|}{ Yes } & \multicolumn{3}{|c|}{ All } & \\
\hline & No & Yes & All & No & Yes & All & No & Yes & All & \\
\hline Mass, initial & 16.0 & 28.5 & 44.5 & 3.1 & 24.7 & 27.9 & 19.1 & 53.2 & 72.3 & 27.7 \\
\hline Average $z_{a}$ & 7.27 & 2.28 & 4.07 & 1.59 & 1.21 & 1.25 & 6.34 & 1.78 & 2.99 & 1.51 \\
\hline Average $z_{n}$ & 1.61 & 1.07 & 1.26 & 1.67 & 1.78 & 1.76 & 1.62 & 1.40 & 1.46 & 7.31 \\
\hline Average $l_{c}$ & 0.46 & 1.71 & 1.26 & 0.16 & 1.74 & 1.56 & 0.41 & 1.72 & 1.38 & 0.01 \\
\hline Mass, stay & 16.0 & 28.5 & 44.5 & 2.8 & 10.7 & 13.5 & 18.8 & 39.2 & 58.0 & 27.0 \\
\hline Average $z_{a}$ & 7.27 & 2.28 & 4.07 & 1.67 & 1.31 & 1.39 & 6.44 & 2.01 & 3.45 & 1.44 \\
\hline Average $z_{n}$ & 1.61 & 1.07 & 1.26 & 1.71 & 1.39 & 1.46 & 1.62 & 1.16 & 1.31 & 7.38 \\
\hline Average $l_{c}$ & 0.46 & 1.71 & 1.26 & 0.16 & 1.51 & 1.23 & 0.42 & 1.65 & 1.26 & 0.02 \\
\hline Mass, switch & 0.0 & 0.0 & 0.0 & 0.4 & 14.0 & 14.4 & 0.4 & 14.0 & 14.4 & 0.7 \\
\hline Average $z_{a}$ & - & - & - & 1.01 & 1.13 & 1.13 & 1.01 & 1.13 & 1.13 & 3.96 \\
\hline Average $z_{n}$ & - & - & - & 1.37 & 2.07 & 2.06 & 1.37 & 2.07 & 2.06 & 4.34 \\
\hline Average $l_{c}$ & - & - & - & 0.14 & 1.92 & 1.87 & 0.14 & 1.92 & 1.87 & 0.00 \\
\hline
\end{tabular}

Table 4: Shares of individuals by types.

Table 4 summarizes the results. Individuals are broken down following the discussion in Section 4 depending on whether they are farmers, $z_{a} \geq \bar{T}\left(z_{n}, l_{c} ; p, r, v\right)$, and whether as farmers they are occupationally and operationally constrained, $z_{a}<$ $T^{\star}\left(z_{n} ; p, r\right)$ and $z_{a}<K^{\star}\left(l_{c} ; p, r\right)$, respectively. First, consider the relative masses of individual types from the first line. We compute that in Ethiopia about 34 percent of farmers are occupationally constrained (i.e., 27.9 percentage points of individuals out of a total mass of 72.3 percentage points of farmers). An even larger fraction is operationally constrained, 74 percent $(=53.2 / 72.3)$.

Splitting farmers along constraints into four groups, we note the following. Only about 22 percent $(=16.0 / 72.3)$ of farmers are unconstrained. The largest fraction at 39 percent $(=28.5 / 72.3)$ consists of operationally but not occupationally constrained types. The second largest group of farmers at 34 percent $(=24.7 / 72.3)$ are constrained on both margins, while very few agricultural workers are occupationally but not operationally constrained, 4 percent $(=3.1 / 72.3)$. A look at the average agricultural skills and communal holdings of these groups reveals that, indeed, the occupationally constrained farmers are predominantly unskilled while the operationally constrained ones are largely land-rich. 
Limited land transferability is often invoked by policymakers as a means to prevent massive (and potentially disruptive) migration flows from rural to urban areas. Assuming that the perception of this pent-up migration pressure is based on current prices, the model rationalizes why a land reform that secures transfer rights is perceived as causing massive occupational switching. At current prices, all of the 34 percent of occupationally constrained farmers would want to switch sectors. Relative price changes, however, undo much of these migration pressures. We find that in general equilibrium only about half of those would-be movers actually make the switch. Also, almost all of these movers are constrained on both margins. This means that the switchers are predominantly relatively unskilled but land-rich farmers, in other words agricultural workers who are "locked into" agriculture due to the threat of expropriation. From the second to last column of Table 4 we see that farmers who switch occupations relative to those that do not have low agricultural skills (1.13 as opposed to 3.45) and detain more land (1.87 as opposed to 1.26). Simultaneously, their non-agricultural skills (2.06) are significantly lower that those of incumbent non-farmers (7.31).

Interestingly, the largest group of farmers, the operationally but not occupationally constrained ones, have no incentive to leave because prices move in their favor. They start out having a comparative advantage in farming, and the land reform only reinforces that as terms of trade shift in their favor: the price of agricultural output increases while the cost of renting land drops. Finally, observe that the equilibrium price changes also induce about 3 percent $(=0.7 / 27.7)$ of non-farmers to switch into agriculture.

\subsection{Policy Variations}

Our model economy features four distinct policy parameters in addition to $\lambda$. Here we examine the extent to which aggregate outcomes are sensitive to these parameters. We change one parameter at a time and re-compute the equilibrium, as summarized in Table 5. This is useful for two reasons. First, it provides insight into the role that the various policy parameters play in shaping the equilibrium. Second, it illustrates 
the impact of the communal regime in economies that are similar to Ethiopia yet differ along one of the policy dimensions.

\begin{tabular}{|c|c|c|c|c|c|c|c|c|c|}
\hline Benchmark, $\lambda=1$ & $\begin{array}{c}\text { Low } \tau \\
0.1\end{array}$ & $\begin{array}{l}\text { High } \tau \\
\quad 1\end{array}$ & $\begin{array}{c}\text { Low } \mu \\
\quad 1\end{array}$ & $\begin{array}{l}\text { High } \mu \\
\rightarrow \infty\end{array}$ & $\begin{array}{l}\text { Low } \phi \\
0.01\end{array}$ & $\begin{array}{l}\text { High } \phi \\
\quad 1\end{array}$ & $\begin{array}{l}\text { Low } \epsilon \\
\rightarrow 0\end{array}$ & $\begin{array}{c}\text { Med. } \epsilon \\
1\end{array}$ & First Best, $\lambda=0$ \\
\hline $\begin{array}{c}\text { Output agriculture, } \\
1.00\end{array}$ & $\begin{array}{l}Y_{a} \\
1.03\end{array}$ & 0.99 & 0.88 & 1.07 & 0.97 & 1.03 & 1.05 & 1.02 & 1.03 \\
\hline $\begin{array}{c}\text { Output non-agricult } \\
1.00\end{array}$ & $\begin{array}{l}\text { ure, } Y_{n} \\
1.03\end{array}$ & 0.99 & 0.98 & 1.01 & 1.01 & 0.99 & 0.98 & 0.99 & 1.13 \\
\hline $\begin{array}{c}\text { GDP at constant pr } \\
1.00\end{array}$ & $\begin{array}{l}\text { ices } \\
1.03\end{array}$ & 0.99 & 0.92 & 1.05 & 0.98 & 1.01 & 1.02 & 1.01 & 1.07 \\
\hline $\begin{array}{l}\text { Agricultural employ } \\
72.3\end{array}$ & $\begin{array}{l}\text { ment, } N_{c} \\
70.3\end{array}$ & $\begin{array}{l}(\%) \\
73.2\end{array}$ & 74.6 & 70.5 & 69.5 & 74.9 & 76.7 & 74.1 & 58.7 \\
\hline $\begin{array}{l}\text { Real agricultural pr } \\
1.00\end{array}$ & ductivit & 0.98 & 0.86 & 1.09 & 1.01 & 0.99 & 0.99 & 0.99 & 1.27 \\
\hline $\begin{array}{c}\text { Non-agricultural pr } \\
1.00\end{array}$ & $\begin{array}{l}\text { ductivit } \\
0.96\end{array}$ & 1.02 & 1.07 & 0.95 & 0.92 & 1.09 & 1.17 & 1.06 & 0.76 \\
\hline $\begin{array}{c}\text { Real APG }\left(Y_{n} / N_{n}\right) \\
1.00\end{array}$ & $\begin{array}{c}/\left(Y_{a} / N_{a}\right. \\
0.91\end{array}$ & 1.04 & 1.25 & 0.87 & 0.91 & 1.10 & 1.18 & 1.07 & 0.60 \\
\hline $\begin{array}{c}\text { Nominal APG }\left(Y_{n} /\right. \\
1.00\end{array}$ & $\begin{array}{l}\left.\mathrm{N}_{n}\right) /(p Y \\
0.93\end{array}$ & $\begin{array}{l}\left(N_{a}\right) \\
1.02\end{array}$ & 0.96 & 0.98 & 0.84 & 1.17 & 1.32 & 1.12 & 0.56 \\
\hline $\begin{array}{c}\text { Agricultural price, } \\
1.00\end{array}$ & 0.97 & 1.02 & 1.31 & 0.89 & 1.09 & 0.94 & 0.89 & 0.96 & 1.06 \\
\hline $\begin{array}{l}\text { Relative rental rate } \\
\qquad 1.00\end{array}$ & $\begin{array}{l}\text { of land, } \\
0.79\end{array}$ & $/ p_{1.12}$ & 4.27 & 0.62 & 1.09 & 0.94 & 0.88 & 0.96 & 0.60 \\
\hline $\begin{array}{c}\text { Variance of }(\log ) \text { op } \\
0.63\end{array}$ & $\begin{array}{c}\text { erations } \\
0.53\end{array}$ & 0.68 & 1.27 & 0.72 & 0.93 & 0.42 & 0.33 & 0.50 & 0.71 \\
\hline $\begin{array}{l}\text { Expropriation rate } \\
0.55\end{array}$ & $\begin{array}{l}\text { \%) } \\
0.55\end{array}$ & 0.53 & 0.39 & 0.42 & 0.53 & 0.61 & 0.88 & 0.59 & - \\
\hline $\begin{array}{l}\text { Landless farmers (\% } \\
6.8\end{array}$ & 7.1 & 6.6 & 5.1 & 5.4 & 34.4 & 0.6 & 10.8 & 7.4 & - \\
\hline $\begin{array}{c}\text { Communal land ren } \\
19.6\end{array}$ & $\begin{array}{l}\text { zed out }( \\
31.3\end{array}$ & 6) 15.9 & 0.8 & 57.8 & 21.9 & 19.1 & 22.3 & 19.5 & - \\
\hline
\end{tabular}

Table 5: Sensitivity to policy parameters

\subsubsection{Maximum Expropriation Hazard Rate $\tau$}

Consider variations of the maximum expropriation hazard $\tau$ from the initial 0.5 to, alternatively, a low 0.1 or the highest possible value of 1 . A decrease in the expropriation threat produces similar qualitative effects to a reduction in $\lambda$, with the exception of 
variables that are not monotonic in $\lambda$ (such as the agricultural price $p$ or the variance in land operations). This is instructive. It shows that the degree of distortions created by our tenure regime can be measured either in the total fraction of communal land $(\lambda)$ or by the maximum expropriation threat. What is perhaps surprising is that the quantitative impact on all the variables considered is larger when passing from $\tau=0.1$ to $\tau=0.5$ than from $\tau=0.5$ to $\tau=1$. In other words, it does not take a high expropriation threat to distort the first-best equilibrium substantially. Even a modest maximum expropriation threat of 10 percent results in a sizable impact.

\subsubsection{Convexity of Expropriation Hazard Rate $\mu$}

Next, consider departures from the calibrated value of $\mu=3.27$, namely to the polar cases $\mu=1$ and $\mu \rightarrow \infty$. A decrease in $\mu$ effectively raises the expropriation threat, playing out similarly to an increase in $\tau$. At $\mu=1$ the expropriation hazard becomes linear in the fraction of rented out land. Loosely speaking, this is a regime where the expropriation threat does not distinguish individuals by their "attachment" to land. Accordingly, farmers become more reluctant to rent out their holdings, almost no land is rented out, and the rental rate shoots up with respect to the calibrated economy. The additional misallocation of land leads to a drop in agricultural output, inducing a large increase in its price $p$. We end up with even more farmers in equilibrium while GDP takes a hit. At the opposite end of the spectrum is the case of $\mu \rightarrow \infty$. Here, individuals can freely rent out land as long as they remain farmers. Operations, therefore, are not distorted, only occupations are. It follows that agricultural output is buoyant. The main adjusting variable here is the price of agricultural output as it plummets to counteract the attractiveness of the agricultural sector. On the whole, GDP is almost as high as in the first-best. To summarize the impact of $\mu$, note that in all scenarios nominal productivity in non-agriculture relative to agriculture is high relative to the first-best. This essentially explains the nominal APG puzzle through occupational barriers that generate a "dual economy." For the communal regime to have a palpable effect on GDP, however, there must also exist distortions on the rental market, brought about by a sufficiently low $\mu$. 


\subsubsection{Maximum Transfer Hazard Rate $\phi$}

We turn to variations in the maximum transfer hazard rate $\phi$ from the initial value of 0.073: a low value 0.01 followed by the highest possible $\phi=1$. In general, an increase in $\phi$ is associated with a decrease in the transfer value $v$ (not shown) as well as a decrease in the fraction of the landless population. While not having a major incidence on GDP, the parameter $\phi$ does strongly affect the two relative sectoral productivity measures. Essentially, a lower $\phi$ increases the role of chance as it magnifies ex-post heterogeneity among farmers. In particular, it leads to a larger fraction of individuals who are landless and therefore do not face any threat of expropriation. Agriculture is relatively less attractive, reflected in lower employment in that sector. Coupled with the operational distortions in agriculture, this raises the equilibrium price of agricultural output. As a result, more of the skilled non-agricultural workers are drawn into farming, implying a drop in non-agricultural productivity. At $\phi=1$, on the other hand, many people are drawn into agriculture as transfers, though small, are guaranteed. The APG opens further because - even more so than in the calibrated economy - agriculture is disproportionately populated by individuals with low skills in any of the two sectors.

\subsubsection{Progressivity of Transfer Hazard Rate $\epsilon$}

The final parameter sensitivity is with respect to $\epsilon$, which governs the progressivity of land reallocation. The calibrated parameter $\epsilon=16.27$ is very high. We perform two variations: a medium value of $\epsilon=1$, and the lowest possible value of $\epsilon \rightarrow 0$. A decrease in $\epsilon$ plays out similarly to an increase in $\phi$. In both cases the dispersion in communal holdings declines, which can also be observed in the reduction in the variance of operations. This means two things. On the one hand there are many marginal individuals that prefer the agricultural sector, resulting in a further increase in the APG measures and more agricultural employment. On the other hand, the decline in the randomness of heterogeneity also implies fewer operational distortions. The agricultural price, therefore, drops. By doing that, it acts as a safety valve that stems occupational misallocation. In terms of GDP, the least pernicious regime is that where reallocation is 
highly progressive. Interestingly, it is also the regime that creates the largest APG, both real and nominal. Finally, a more progressive reallocation policy actually generates a larger fraction of landless farmers, due to a higher realized expropriation rate. Farmers become less reluctant to rent out land and risk expropriation because the likelihood of recovering their holdings (i.e., their one transfer) is high.

\section{Conclusion}

Agricultural productivity in developing countries is surprisingly low. The reason, according to a growing macro development literature, may well be found in the misallocation of resources as measured by proxy wedges to optimality conditions. Particular attention is paid to misallocation of land operations across producers, and misallocation of labor across occupations. This paper presents a micro-foundation that endogenizes such distortions in an otherwise standard selection and production model.

For this we formalize stylized policies that capture key elements of land tenure systems observed across many developing countries. We emphasize the role of limited transferability of land by which individuals are only exposed to the risk of expropriation when they rent out land. By doing that we heed the lessons from the micro development literature which states that de jure tenure insecurity (e.g. in the form of no formal land registration) does not necessarily imply de facto tenure insecurity, as exemplified in the debate on tenure security and investment (Fenske, 2011). We do, however, take a strong position on the fact that the threat of expropriation has bite when farmers decide to turn user rights into commercial value by renting out land, in particular when they stop farming altogether.

Our principal findings are as follows. Restoring land transferability in an economy where all land is communal results in a substantial decrease in agricultural employment of 19 percent. It is also associated with a decline of $40 \%$ and $44 \%$, respectively, in the real and nominal agricultural productivity gaps. The increase in aggregate productivity (GDP) of $7 \%$, on the other hand, is more modest. These quantifications are based on Ethiopia. Economies with lower fractions of aggregate communal land can expect 
proportionately smaller effects following land liberalization. Larger effects, on the other hand, can be expected in similar economies where restrictions on out-rentals are more stringent.

Who are the individuals that prefer agricultural employment under the communal land tenure regime, but not otherwise? They are a sizable group of marginal individuals who - compared to the average worker - are relatively unskilled in any of the two sectors. Under communal tenure they are pulled into agriculture to preserve their land rights, driving down the average productivity in that sector. Ultimately, however, these marginal workers are not sufficiently skilled in either sector to have a major incidence on aggregate productivity. There is also operational misallocation, witnessed by the large share of farmers with excessive land operations. Occupational misallocation, though, is a more powerful force as the relative price of agricultural output is low.

Our exercise offers the following lessons. First, much of the real and especially nominal APG in poor economies may indeed result from obstacles to land transferability. To the extent that selection plays a key role, our results echo the findings of Lagakos and Waugh (2013), though in our case the occupational selection pattern is distorted. Second, the removal of obstacles to land transferability results in aggregate benefits, but it falls short of producing a first-order impact on aggregate productivity. This implies that lowering the real and nominal APG in developing countries does not by itself entail the solution to the development puzzle. To be sure, an extension of our framework to include endogenous investment and other refinements may still produce larger losses associated with communal land. Our framework, however, also rules out by assumption any potential benefits of communal land. Since institutions that limit land transferability are prevalent around the world, they certainly exist to correct some undesirable outcomes. They may, for example, address issues such as inequality, myopic behavior or incomplete insurance, in particular in economies with few other public policy instruments. Our results are therefore silent on the ultimate welfare consequences of communal land tenure. We leave it to future research to weigh its distortionary effects against any potential benefits. 


\section{Appendix}

\subsection{Cross-Country Data}

In this subsection we outline our measures of the agricultural productivity gap across countries. We also show that these measures relate to a particular index on tenure insecurity.

\subsubsection{Agricultural Productivity Gaps across Countries}

To construct the nominal agricultural productivity gap (APG) we use 2005 World Bank data on the ratio of the non-agricultural value-added share, $p_{n} Y_{n} /\left(p_{a} Y_{a}+p_{n} Y_{n}\right)$, to the agricultural share, $p_{a} Y_{a} /\left(p_{a} Y_{a}+p_{n} Y_{n}\right)$, measured in current USD, and adjusted by levels of employment $N$ in each sector. The nominal agricultural productivity gap (APG) of country $i$ is hence $A P G_{n o m}^{i}=\frac{\left(p_{n}^{i} Y_{n}^{i}\right) / N_{n}^{i}}{\left(p_{a}^{i} Y_{a}^{i}\right) / N_{a}^{i}}$.

\begin{tabular}{ccccc}
\hline \hline Decile & $\mathrm{N}$ & Real APG & $\mathrm{N}$ & Nominal APG \\
\hline 1 & 11 & 22.92 & 13 & 6.02 \\
2 & 11 & 20.02 & 13 & 4.66 \\
3 & 11 & 17.16 & 13 & 3.52 \\
4 & 11 & 11.45 & 13 & 2.39 \\
5 & 11 & 10.17 & 13 & 2.54 \\
6 & 11 & 5.37 & 13 & 2.08 \\
7 & 11 & 4.39 & 13 & 2.76 \\
8 & 11 & 3.57 & 13 & 2.85 \\
9 & 11 & 3.15 & 13 & 1.64 \\
10 & 11 & 2.90 & 13 & 1.70 \\
\hline Total & 110 & 10.11 & 130 & 2.92 \\
\hline
\end{tabular}

Table 6: Real and nominal relative APG (U.S.=1)

The computation of the real APG is more tricky. It again involves the use of 2005 World Bank data as well as data from the Food and Agricultural Organisation (FAO) for the years 2004-2005. First, we start from the identity:

$$
p_{a}^{W B} Y_{a}^{i}+p_{n}^{W B} Y_{n}^{i}=p^{W B} Y^{i}
$$

This decomposes country $i$ 's real GDP measured in World Bank international dollars $p^{W B} Y^{i}$ into real sectoral components of value-added evaluated at each sector's respective international price. Since neither $p_{a}^{W B} Y_{a}^{i}$ nor $p_{n}^{W B} Y_{n}^{i}$ are available we pro- 
ceed with FAO data and make two critical assumptions. The FAO collects countryspecific industry-level prices for agricultural output in order to measure gross output $(O)$ in international FAO dollars, $p_{a}^{F A O, O} O_{a}^{i}$. These are hence cross-country data on real agricultural output, but not real valued-added, since for years other than 1985 the FAO does not collect prices for (non-agricultural) intermediate inputs used in agriculture. In order to obtain real value-added in agriculture we make the assumption that $p_{a}^{F A O, O} / p_{a}^{i, O}=p_{a}^{F A O} / p_{a}^{i}$, i.e. the ratio between international and local industry prices equals the ratio between international and local value-added deflators. This gives $p_{a}^{F A O} Y_{a}^{i}=\frac{p_{a}^{F A O, O} O_{a}^{i}}{p_{a}^{i, O} O_{a}^{i}} p_{a}^{i} Y_{a}^{i}$. World Bank data on agricultural value-added in current USD, $p_{a}^{i} Y_{a}^{i}$, coupled with FAO data on gross agricultural output in international and current USD, respectively, $p_{a}^{F A O, O} O_{a}^{i}$ and $p_{a}^{i, O} O_{a}^{i}$, thus translate into the real measure of value-added in agriculture, $p_{a}^{F A O} Y_{a}^{i}$. The second assumption is to translate those into World Bank international prices by a factor of proportionality so that $p_{a}^{W B} Y_{a}^{U S}=\alpha p_{a}^{F A O} Y_{a}^{i}$. We proceed as in Caselli (2005) by noting that given the size of the U.S. in the construction of international prices one can assume $p_{a}^{W B} Y_{a}^{U S}=p_{a}^{U S} Y_{a}^{U S}$. From that we have that $\alpha=\frac{p_{a}^{U S, O} O_{a}^{U S}}{p_{a}^{F A O, O} O_{a}^{U S}}$. With $p_{a}^{W B} Y_{a}^{i}$ in hand we can hence compute $p_{n}^{W B} Y_{n}^{i}$ from (8). Finally, the real agricultural gap is hence $A P G_{\text {real }}^{i}=\frac{\left(p_{n}^{W B} Y_{n}^{i}\right) / N_{n}^{i}}{\left(p_{a}^{W B} Y_{a}^{i}\right) / N_{a}^{i}}$.

Table 6 ranks both measurements of APG (normalized to the U.S.) in deciles according to real GDP per capita (in PPP) and reports the average APG for each group. ${ }^{33}$ Clearly, the APG is decreasing in GDP per capita, and comparing the first and last deciles gives factor differences of $22.92 / 2.90=7.9$ and $6.02 / 1.70=3.5$ for the real and nominal measures, respectively.

\subsubsection{Agricultural Productivity Gaps and Tenure Insecurity}

The Institutional Profiles Database (IPD) of the Centre d'Etudes Prospectives et d'Informations (CEPII), provides an index on land tenure insecurity that covers a large number of countries. The indicator ranges between 0 and 4 and is increasing in tenure

\footnotetext{
${ }^{33}$ We drop countries smaller than 1,000 square kilometers in size. We also drop Burundi, Guyana, Libya, Guyana which are clear outliers in terms of relative nominal agricultural productivity. This does not significantly affect the results.
} 


\begin{tabular}{|c|c|c|c|c|}
\hline & $\begin{array}{c}1) \\
\text { Nom. APG (log) }\end{array}$ & $\begin{array}{c}(2) \\
\text { GDP per capita }(\log ) \\
\end{array}$ & $\begin{array}{c}\text { (3) } \\
\text { Nom. APG (log) }\end{array}$ & $\begin{array}{c}(4) \\
\text { GDP per capita }(\log ) \\
\end{array}$ \\
\hline Real APG (log) & $\begin{array}{c}-0.278^{* * *} \\
(-5.90)\end{array}$ & $\begin{array}{c}-0.598^{* * *} \\
(-10.07)\end{array}$ & & \\
\hline Land tenure insecurity & & & $\begin{array}{c}0.226^{* * *} \\
(3.89)\end{array}$ & $\begin{array}{c}0.540^{* * *} \\
(6.97)\end{array}$ \\
\hline Constant & $\begin{array}{c}3.171^{* * *} \\
(7.69) \\
\end{array}$ & $\begin{array}{c}7.027^{* * *} \\
(13.37) \\
\end{array}$ & $\begin{array}{c}0.383^{* *} \\
(3.19)\end{array}$ & $\begin{array}{c}0.833^{* * *} \\
(5.30) \\
\end{array}$ \\
\hline Observations & 130 & 110 & 119 & 102 \\
\hline
\end{tabular}

Table 7: APG and tenure insecurity

insecurity. It is constructed on the basis of answers to four aspects of tenure security, namely (1) the importance of land expropriation practices, (2) the importance of land issues in local politics/media, (3) the share of the urban population with tenure rights that are not formally recognized, and (4) the share of the rural population with tenure rights that are not formally recognized. In Table 7 we regress our measures of nominal and real APG differences on the IPD indicator. The results suggest a statistically significant relationship whereby high levels of tenure insecurity are systematically positively related to both the real and nominal APG. For comparison we also regress the APG measures on GDP per capita.

\subsection{Theory}

Here we present the definition of the stationary equilibrium as well as proofs of the propositions.

\subsubsection{Definition of the Stationary Equilibrium}

For an equilibrium to exist the economy must be sufficiently productive to ensure that the subsistence requirement in agricultural goods is met, $Y_{a}>\bar{a}$. The stationary equilibrium is defined as the set of individual allocations $b(x), \mathbb{1}_{a}(x), l(x), y_{a}(x), w_{a}(x)$, $\forall x$; policy outcomes $\pi_{E}(x), \pi_{R}(x)$, and $l_{c}^{\prime}(x), \forall x$; prices $w_{n}(x), p$ and $r$; aggregate allocations $C_{a}, C_{n}, E, Y_{n}$, and $Y_{a}$; the transfer value $v$; as well as a stationary distribution 
$H(x)$, such that:

- all agents of type $x$ solve their maximization problem;

- the representative non-agricultural firm maximizes profits;

- the aggregate stand-in household solves its maximization problem;

- the agricultural market clears: $C_{a}=Y_{a}=\int y_{a}(x) \mathrm{d} H(x)$;

- the non-agricultural market clears: $C_{n}=Y_{n}$;

- the non-agricultural labor market clears: $E=\int\left[1-\mathbb{1}_{a}(x)\right] z_{n}(x)$;

- the aggregate land market clears: $\int l(x) \mathrm{d} H(x)=L$;

- expropriation equals redistribution: $\int l_{c}(x) \mathrm{d} H(x)=\lambda L$;

- the stationary distribution $H(x)$ is consistent:

The stationary equilibrium always features positive expropriation and reallocation because skills change through time. A changing skill set implies that at any point there always exists a positive mass of farmers who are sufficiently unskilled so as to rent out land, resulting in positive expropriation. The distribution of communal holdings therefore cannot be static, meaning that it is less likely to depend on initial conditions. Indeed, our numerical simulations around the calibrated economy suggest that distinct initial conditions all lead to the same stationary distribution. We do not, however, provide an analytic prove of its uniqueness.

\subsubsection{Proof of Proposition 1}

Conditional on farming $\left(\mathbb{1}_{a}=1\right)$ the first-order condition with respect to $l$ from the value function (3) implies

$$
\gamma p z_{a}^{1-\gamma} l^{\gamma-1}=r+M
$$


where

$$
\begin{aligned}
M \equiv \frac{\partial \pi_{E}\left(l_{c}, l\right)}{\partial l} \beta( & \pi_{R}\left(l_{c}, \mathbb{1}_{a}\right) \mathbb{E}_{z^{\prime} \mid z}\left[V\left(z_{a}^{\prime}, z_{n}^{\prime}, l_{c}+v\right)-V\left(z_{a}^{\prime}, z_{n}^{\prime}, v\right)\right] \\
& \left.+\left[1-\pi_{R}\left(l_{c}, \mathbb{1}_{a}\right)\right] \mathbb{E}_{z^{\prime} \mid z}\left[V\left(z_{a}^{\prime}, z_{n}^{\prime}, l_{c}\right)-V\left(z_{a}^{\prime}, z_{n}^{\prime}, 0\right)\right]\right) .
\end{aligned}
$$

Since $V$ is strictly increasing in $l_{c}, M=0$ if and only if $\frac{\partial \pi_{E}\left(l_{c}, l\right)}{\partial l}=0$ (which is the case when $l \geq l_{c}$ ). Otherwise it must be that $M>0$ when $\frac{\partial \pi_{E}\left(l_{c}, l\right)}{\partial l}>0$ (which is the case when $l<l_{c}$ ). Two cases are thus possible. First, if $l \geq l_{c}$ we have $M=0$ and the first-order condition results in $l=l^{\star}$. From the definition of $K^{\star}$ from (6) this implies that $z_{a} \geq K^{\star}$. On the contrary, if $l<l_{c}$, the first-order condition states that $l>l^{\star}$. This implies that $l_{c}>l^{\star}$. After replacing the expression of $l^{\star}$ we have that $z_{a}<K^{\star}$.

\subsubsection{Proof of Proposition 2}

Comparing the value function (3) under the two sectoral choices we have that $\mathbb{1}_{a}=1$ if and only if

$$
w_{a}\left(z_{a}, l ; p, r\right)+M(l) \geq z_{n}
$$

where

$$
\begin{aligned}
M(l) \equiv \beta\{ & {\left[\tau-\pi_{E}\left(l_{c}, l\right)\right]\left(\mathbb{E}_{z^{\prime} \mid z}\left[V\left(z_{a}^{\prime}, z_{n}^{\prime}, l_{c}\right)-V\left(z_{a}^{\prime}, z_{n}^{\prime}, 0\right)\right]\right) } \\
& +\pi_{R}\left(l_{c}, 1\right)\left[1-\pi_{E}\left(l_{c}, l\right)\right]\left(\mathbb{E}_{z^{\prime} \mid z}\left[V\left(z_{a}^{\prime}, z_{n}^{\prime}, l_{c}+v\right)-V\left(z_{a}^{\prime}, z_{n}^{\prime}, l_{c}\right)\right]\right) \\
& \left.+\pi_{R}\left(l_{c}, 1\right) \pi_{E}\left(l_{c}, l\right)\left(\mathbb{E}_{z^{\prime} \mid z}\left[V\left(z_{a}^{\prime}, z_{n}^{\prime}, v\right)-V\left(z_{a}^{\prime}, z_{n}^{\prime}, 0\right)\right]\right)\right\} .
\end{aligned}
$$

The continuation difference term under any strictly positive choice of land operations $l>0$ is strictly positive, $M(l)>0$. Let $z_{a}=\bar{T}$ denote the threshold value for which the individual is indifferent between the two activities:

$$
w_{a}(\bar{T}, l ; p, r)+M(l)=z_{n} .
$$


The indifferent farmer can be of two types. Either his land choice is non-distorted, i.e. $l=l^{\star}$, resulting in $w_{a}(\bar{T}, l ; p, r)=w_{a}^{\star}(\bar{T} ; p, r)$. In that case we have

$$
w_{a}^{\star}(\bar{T} ; p, r)+M\left(l^{\star}\right)=z_{n} .
$$

Alternatively, the indifferent farmer's land choice is distorted, i.e. $l>l^{\star}$. If the indifferent farmer, instead, chose non-distorted land operations $l=l^{\star}$, agriculture would no longer be the optimal sector:

$$
w_{a}^{\star}(\bar{T} ; p, r)+M\left(l^{\star}\right)<z_{n} .
$$

Combining equations (5) and (7) results in $w_{a}^{\star}(\bar{T} ; p, r)=\frac{\bar{T}}{T^{\star}} z_{n}$. Replacing this expression in (9) and (10), respectively, yields

$$
\frac{\bar{T}}{T^{\star}} z_{n}+M\left(l^{\star}\right)=z_{n}
$$

and

$$
\frac{\bar{T}}{T^{\star}} z_{n}+M\left(l^{\star}\right)<z_{n}
$$

Since $M\left(l^{\star}\right)>0$, it must be that in in either of the two cases $\bar{T}<T^{\star}$. Finally, notice that the threshold value of $\bar{T}$, through $M(l)$, depends on the individual's continuation which is a function of $z_{n}, l_{c}$ and $v$, in addition to $p$ and $r: \bar{T}=\bar{T}\left(z_{n}, l_{c} ; p, r, v\right)$.

\subsection{Empirical Moments}

In this subsection we explain the construction of the empirical moments used in the calibration.

\subsubsection{LSMS-ISA Ethiopia}

Most of our empirical moments are based on the Ethiopian LSMS-ISA panel dataset over the two existing waves 2011-2012 and 2013-2014. We rely on the panel dimension to back out permanent components in order to weed out transitory shocks (in income, farm output) and measurement errors. 
Our first moment is the dispersion in non-agricultural wages, $w_{n}$. First, we construct a panel of individuals and measure hourly wages for the two waves. We run an OLS regression of $(\log )$ wages on a set of individual and time dummies, and then compute the variance of the individual dummies to be 0.831 .

The second moment is the dispersion in land operations $l$. The unit of our model is an individual while its empirical part is a family farm. This is why we target the ratio of land operations relative to farm labor. ${ }^{34}$ We construct a panel where land operations include all the land used, namely the sum of fields on which staple crops are planted. As for labor, we count the number of individuals (household labor, hired labor and free labor) involved in planting and harvesting activities on staple crop fields, and aggregate this measure up to the household level. The resulting ratio is regressed via OLS on a set of individual and time dummies. The variance of the individual dummies, 0.630, represents our target.

Beyond the moments that are used for the purpose of the calibration, we also compute three empirical moments that will allow us to gauge the performance of our model. First, we compute the dispersion of talent $z_{a}$ conditional on running a farm. From the model, agricultural skills equal $z_{a}=\left(y_{a} / l\right)^{\frac{1}{1-\gamma}} l$. For the empirical counterpart we measure $l$ again to be land operations per unit of farm labor while $y_{a}$ is agricultural output per unit of farm labor. ${ }^{35}$ To compute output we measure output in kilograms per field, the product of field size by the dry weight of the output on $2 \mathrm{x} 2 \mathrm{sqm}$, which we multiply by the average national price of the crop planted on that field. Our sample is restricted to pure stand fields for which we have output per kilograms measurement, GPS measurement, and prices. These field-level measures are aggregated at the household level. The resulting empirical measure $z_{a}$ is regressed via OLS on a set of individual and time dummies. The variance of the individual dummies equals 1.23.

\footnotetext{
${ }^{34}$ In particular, we posit that the empirical production function is $y=(z n)^{1-\gamma} \tilde{l}^{\gamma}=z^{1-\gamma} l^{\gamma} n$ where $\tilde{l}$ is total operations, $n$ is total hours worked, and $l$ is the ratio of the two.

${ }^{35}$ The empirical production function, of course, also includes factors such as physical capital, intermediate goods, etc. Here we abstract from measuring these directly. By assuming that these factors enter log-linearly in the production function and farmers choose them competitively, the dispersion in $z_{a}$ is preserved.
} 
Our second non-targeted moment is the dispersion of land ownership, $l_{c}$. To measure land ownership at the household level we focus on a sample of field level measurements for cultivated fields (pure stand and mixed crop). In particular, a household's land ownership comprises two parts. First, its operated parcels that are granted by local leaders and inherited to be owned (excluding parcels that are rented/borrowed for free/moved in without permission, which are considered to be rented in). Second, owned parcels that are rented out. These are directly given in wave 2 , while for wave 1 we only have information on how many fields on a particular parcel have been rented out. To infer the size of the land rented out, we assume that the fields within a parcel (on which there is rental-out activity) are of equal size. We then aggregate the parcel level variables at the holder level, before aggregating them to the household level. Finally, we divide by total labor supply as computed above. The resulting ratio is regressed via OLS on a set of individual and time dummies. The variance of the individual dummies, 0.61, represents the dispersion in the permanent component of $l_{c}$. The final non-targeted moment is the correlation between $(\log )$ operations per labor supply and (log) ownership per labor supply. It amounts to 0.66 and 0.85 , respectively, in the two waves. The figure reported in the Section on calibration is the simple average of 0.75 .

\subsubsection{Own Data Collection}

In December 2014, we interviewed randomly selected households in seven villages (kebele) across four sub-regions (woreda) in Ethiopia's two main regions (Amhara and Oromia). In combination, the chosen locations in South Wollo and Arsi are as close to representativeness of Ethiopian agriculture as one can get in a small sample. In each village, we interviewed six to seven households to obtain a sample of 44 households. In each village, we complemented a formal survey with a large number of semi-structured focus group discussions and key informant interviews (village leaders, land committee members and extension workers).

A section of the questionnaire is devoted to land expropriation and redistribution. As part of our section on land expropriation and redistribution, household heads were 


\begin{tabular}{lcc}
\hline \hline & Mean & Sample Size \\
\hline Expropriation & 0.068 & 44 \\
Expropriation parents & 0.36 & 44 \\
Age household head & 48.5 & 44 \\
Age children & 21.8 & 28 \\
\hline Source: Own dataset. \\
\multicolumn{2}{c}{ Table 8: Expropriation statistics }
\end{tabular}

asked whether one of their household members has been subject to land expropriation since household formation - see Table 8. Responses suggest that $6.8 \%$ have experienced expropriation in Ethiopia. We consider this number to be rather low in light of the numerous episodes of land expropriation and redistribution that have taken place in Ethiopia over the last four decades. This is confirmed by further evidence from our dataset, which documents that $36 \%$ of the parents of the household head (or spouse) experienced expropriation.

Since we calibrate the model to annual frequency we adjust these expropriation rates to annualized values and divide the expropriation rate by the average number of years since household formation, which gives us a lower bound of $0.25 \%$. Doing the same adjustment with the expropriation rate on the parents of the household head, and adjusting it by the average generational length of 43 years (totalling to a life expectancy of 63 years in Ethiopia) gives us an upper bound of $0.85 \%$ for the expropriation rate. We take the mean of the upper and lower bounds and hence target a mean rate of $0.55 \%$.

\section{References}

Adamopoulos, Tasso and Diego Restuccia, "Land Reform and Productivity: A Quantitative Analysis with Micro Data," Unpublished manuscript, University of Toronto, December 2014.

_ and _, "The Size Distribution of Farms and International Productivity Differences," American Economic Review, 2014, 104 (6), 1667-97. 
_, Loren Brandt, Jessica Leight, and Diego Restuccia, "Misallocation, Selection and Productivity: A Quantitative Analysis with Panel Data from China," Unpublished manuscript, University of Toronto, 2016.

Ali, Daniel Ayalew, Stefan Dercon, and Madhur Gautam, "Property Rights in a Very Poor Country: Tenure Insecurity and Investment in Ethiopia," Agricultural Economics, 2011, 42 (1), 75-86.

Atwood, David A., "Land Registration in Africa: The Impact on Agricultural Production," World Development, 1990, 18 (5), 659-71.

Benin, Samuel and John L. Pender, "Land Rental and Land Management in the Ethiopian Highlands," in Stein T. Holden, Keijiro Otsuka, and Frank M Place, eds., The Emergence of Land Markets in Africa. Impacts on Poverty, Equity, and Efficiency, Washington, D.C.: Resources for the Future, 2009, pp. 213-37.

Besley, Timothy, "Property Rights and Investment Incentives: Theory and Evidence from Ghana," Journal of Political Economy, 1995, 103 (5), 903-937.

Bomuhangi, Alan, Cheryl Doss, and Ruth Meinzen-Dick, "Who Owns the Land? Perspectives from Rural Ugandans and Implications for Land Acquisition," IFPRI Discussion Paper, 2011, (01136).

Brasselle, Anne-Sophie, Frédéric Gaspart, and Jean-Philippe Platteau, "Land Tenure Security and Investment Incentives: Puzzling Evidence from Burkina Faso," Journal of Development Economics, 2002, 67 (2), 373-418.

Bruce, John and Shem Migot-Adholla, Searching for Land Tenure Security in Africa, Dubuque, Iowa: Kendall/Hunt, 1994.

Byamugisha, Frank F. K., Securing Africa's Land for Shared Prosperity: a program to scale up reforms and investments, Washington, D.C.: The World Bank, 2013. 
Caselli, Francesco, "Accounting for Cross-Country Income Differences," in Philippe Aghion and Steven Durlauf, eds., Handbook of Economic Growth, Vol. 1, Elsevier, 2005, chapter 9, pp. 679-741.

Chen, Chaoran, "Untitled Land, Occupational Choice, and Agricultural Productivity," Unpublished manuscript, University of Toronto, 2016.

de Brauw, Alan and Valerie Mueller, "Do Limitations in Land Rights Transferability Influence Mobility Rates in Ethiopia," Journal of African Economies, 2012, $21(4), 548-579$.

de Janvry, Alain, Kyle Emerick, Marco Gonzales-Navarro, and Elisabeth Sadoulet, "Delinking Land Rights from Land Use: Certification and Migration in Mexico," American Economic Review, 2015, 105 (10), 3125-49.

Deininger, Klaus and Songqing Jin, "Tenure Security and Land-Related Investments: Evidence from Ethiopia," European Economic Review, 2006, 50 (5), 1245-77.

_ and _, "Land Rental Markets in the Process of Rural Structural Transformation: Productivity and Equity Impacts from China," Journal of Comparative Economics, 2009, 37 (4), 629-46.

_, Daniel Ayalew Ali, Stein Holden, and Jaap Zevenbergen, "Rural Land Certification in Ethiopia: Process, Initial Impact, and Implications for Other African Countries," World Development, 2008, 36 (10), 1786-812.

_, Songqing Jin, Mulat Demeke, Berhanu Adenew, and Samuel GebreSelassie, "Market and Non-Market Transfers of Land in Ethiopia: Implications for Efficiency, Equity and Non-farm Development," World Bank Policy Research Working Paper Series, 2003, 2992.

Dercon, Stefan and Pramila Krishnan, "Land Rights Revisited," in Tim Besley and Rajshri Jayraman, eds., The Microeconomics of Institutions, MIT Press, 2010. 
Do, Quy-Toan and Lakshmi Iyer, "Land Titling and Rural Transition in Vietnam," Economic Development and Cultural Change, 2008, 56, 531-79.

Donovan, Kevin, "Agricultural Risk, Intermediate Inputs, and Cross-Country Productivity Differences," Unpublished manuscricpt, University of Notre Dame, 2016.

Ege, Svein, "The Promised Land: The Amhara Land Redistribution of 1997," Norwegian University of Science and Technology Working Paper, 1997.

Feder, Gershon, "The Relation Between Farm Size and Farm Productivity," Journal of Development Economics, 1985, 18, 297-313.

Fenske, James, "Land Tenure and Investment Incentives: Evidence from West Africa," Journal of Development Economics, 2011, 95 (2), 137-56.

Field, Erica, "Entitled to Work: Urban Property Rights and Labor Supply in Peru," The Quarterly Journal of Economics, November 2007, 122 (4), 1561-1602.

Goldstein, Markus and Christopher Udry, "The Profits of Power: Land Rights and Agricultural Investment in Ghana," Journal of Political Economy, 2008, 116 (6), $981-1022$.

Gollin, Douglas and Richard Rogerson, "Productivity, Transport Costs, and Subsistence Agriculture," Journal of Development Economics, 2014, 107, 38-48.

_ , David Lagakos, and Michael E. Waugh, "Agricultural Productivity Differences across Countries," American Economic Review: Papers and Proceedings, 2014, 104 (5), 165-70.

_ , _ , and _ , "The Agricultural Productivity Gap," Quarterly Journal of Economics, 2014, 129 (2), 939-93.

_, Stephen Parente, and Richard Rogerson, "Farm Work, Home Work, and International Productivity Differences," Review of Economic Dynamics, 2004, 7 (4), $827-50$. 
Harris, John R. and Michael P. Todaro, "Migration, Unemployment and Development: A Two-Sector Analysis," American Economic Review, 1970, 60 (1), 126-142.

Herrendorf, Berthold and Todd Schoellman, "Wages, Human Capital, and Structural Transformation," Unpublished manuscript, Arizona State University, 2015.

Holden, Stein T., Keijiro Otsuka, and Frank M. Place, The Emergence of Land Markets in Africa. Impacts on Poverty, Equity, and Efficiency, Washington, D.C.: Resources for the Future, 2009.

Jacoby, Hanan, Guo Li, and Scott Rozelle, "Hazards of Expropriation: Tenure Insecurity and Investment in Rural China," American Economic Review, 2002, 92 (5), 1420-47.

Lagakos, David and Michael Waugh, "Selection, Agriculture, and Cross-Country Productivity Differences," American Economic Review, 2013, 103 (2), 948-80.

Lewis, W. Arthur, "Economic Development with Unlimited Supplies of Labour," The Manchester School, May 1954, 22 (2), 139-191.

Macours, Karen, Alain de Janvry, and Elisabeth Sadoulet, "Insecurity of Property Rights and Matching in the Tenancy Market," European Economic Review, 2010, $54(7), 880-99$.

McMillan, Margaret S. and Dani Rodrik, "Globalization, Structural Change and Productivity Growth," NBER Working Paper Series, 2011, (17143).

Mundlak, Yair, "Economic Growth: Lessons from Two Centuries of American Agriculture," Journal of Economic Literature, 2005, 43 (4), 989-1024.

Pande, Rohini and Christopher. Udry, "Institutions and Development: A View from Below," Proceedings of the 9th World Congress of the Econometric Society., 2005 . 
Place, Frank M., "Land Tenure and Agricultural Productivity in Africa: A Comparative Analysis of the Economics Literature and Recent Policy Strategies and Reforms," World Development, 2009, 37 (8), 1326-36.

_ and Keijiro Otsuka, "Land Tenure Systems and Their Impacts on Agricultural Investments and Productivity in Uganda," Journal of Development Economics, 2002, 38 (6), 105-28.

Rahmato, Dessalen, Agrarian Reform in Ethiopia, Uppsala, Sweden: Scandinavian Institute for African Studies, 1984.

_, Access to Resources and Livelihood Insecurity, Addis Ababa: Forum for Social Studies, 2003.

_ , Searching for Tenure Security, Addis Ababa: Forum for Social Studies, 2004.

Restuccia, Diego and Raül Santaeulàlia-Llopis, "Land Misallocation and Productivity," Unpublished manuscript, University of Toronto, 2015.

_, Dennis Tao Yang, and Xiaodong Zhu, "Agriculture and Aggregate Productivity: A Quantitative Cross-Country Analysis," Journal of Monetary Economics, March 2008, 55 (2), 234-250.

Rosenzweig, Mark R. and Kenneth I. Wolpin, "Credit Market Constraints, Consumption Smoothing, and the Accumulation of Durable Production Assets in LowIncome Countries: Investments in Bullocks in India," Journal of Political Economy, 1993, $101(2), 223$.

Sjaastad, Espen and Daniel Bromley, "Indigenous Land Rights in Sub-Saharan Africa: Appropriation, Security and Investment Demand," World Development, 1997, 25 (4), 549-62.

Valentinyi, Akos and Berthold Herrendorf, "Measuring Factor Income Shares at the Sectoral Level," Review of Economic Dynamics, 2008, 11 (4), 820-35. 
Vollrath, Dietrich, "How Important are Dual Economy Effects for Aggregate Productivity?," Journal of Development Economics, 2009, 88 (2), 325-334.

Young, Alwyn, "Inequality, the Rural-Urban Gap and Migration," Quarterly Journal of Economics, 2013, 128 (4), 1727-85. 